\title{
Moisture in clothing and its transient influence on human thermal responses through clothing microenvironment in cold environments in winter
}

Article

Accepted Version

Creative Commons: Attribution-Noncommercial-No Derivative Works 4.0

Du, C., Li, B., Yu, W., Liu, H., Li, C. and Yao, R. (2019)

Moisture in clothing and its transient influence on human thermal responses through clothing microenvironment in cold environments in winter. Building and Environment, 150. pp. 112. ISSN 0360-1323 doi:

https://doi.org/10.1016/j.buildenv.2018.12.066 Available at https://centaur.reading.ac.uk/81735/

It is advisable to refer to the publisher's version if you intend to cite from the work. See Guidance on citing.

To link to this article DOI: http://dx.doi.org/10.1016/j.buildenv.2018.12.066

Publisher: Elsevier

All outputs in CentAUR are protected by Intellectual Property Rights law, including copyright law. Copyright and IPR is retained by the creators or other copyright holders. Terms and conditions for use of this material are defined in the End User Agreement. 


\section{www.reading.ac.uk/centaur}

\section{CentAUR}

Central Archive at the University of Reading

Reading's research outputs online 
Building and Environment 150 (2019) 1-12

Contents lists available at ScienceDirec

Building and Environment

Moisture in clothing and its transient influence on human thermal responses through clothing microenvironment in cold environments in winter

Chenqiu Du ${ }^{\mathrm{a}, \mathrm{b}, * *}$, Baizhan $\mathrm{Li}^{\mathrm{a}, \mathrm{b}, *}$, Wei $\mathrm{Yu}^{\mathrm{a}, \mathrm{b}}$, Hong $\mathrm{Liu}^{\mathrm{a}, \mathrm{b}}$, Chao $\mathrm{Li}^{\mathrm{a}}{ }^{\mathrm{a} b}$, Runming $\mathrm{Yao}^{\mathrm{a}, \mathrm{c}}$

a Joint International Research Laboratory of Green Buildings and Built Environments (Ministry of Education), Chongqing University, Chongqing 400045, China ${ }^{b}$ National Centre for International Research of Low-carbon and Green Buildings (Ministry of Science and Technology), Chongqing University, Chongqing 400045, Chine ${ }^{c}$ School of the Built Environment, University of Reading Reading RG6 6AW, UK

Moisture in clothing and its transient influence on human thermal responses through clothing microenvironment in cold environments in winter

Chenqiu Du ${ }^{\mathrm{a}, \mathrm{b}^{*}}$, Baizhan $\mathrm{Li}^{\mathrm{a}, \mathrm{b}^{*}}$, Wei Yu${ }^{\mathrm{a}, \mathrm{b}}$, Hong Liu ${ }^{\mathrm{a}, \mathrm{b}}$, Chao $\mathrm{Li}^{\mathrm{a}, \mathrm{b}}$, Runming Yao

\author{
Affiliation:

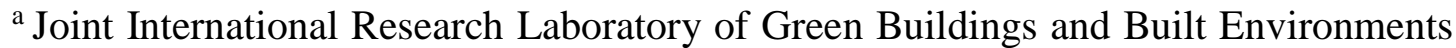 \\ (Ministry of Education), Chongqing University, Chongqing 400045, China \\ ${ }^{b}$ National Centre for International Research of Low-carbon and Green Buildings \\ (Ministry of Science and Technology), Chongqing University, Chongqing 400045, \\ China \\ ${ }^{c}$ School of the Built Environment, University of Reading, Reading RG6 6AW, UK
}

Building and Environment, Volume 150, March 2019, Pages 1-12

https://doi.org/10.1016/j.buildenv.2018.12.066

\title{
Abstract:
}

Air humidity produces conditions of varying moisture contents in clothing, which affects the heat and moisture transfer between human body, clothing and environment, as well as the wearers' comfort. This study was designed to evaluate the moisture effects in clothing in cold environments. A series of wearing experiments were conducted in a climate chamber, simulating transient moisture absorption and desorption in experimental clothes. Totally 20 subjects were involved in three temperature levels (16 ${ }^{\circ} \mathrm{C} / 20{ }^{\circ} \mathrm{C} / 24{ }^{\circ} \mathrm{C}$ ) and two relative humidity levels $(15 \% \mathrm{RH} / 85 \% \mathrm{RH})$ during winter, with physiological measurement and subjective evaluation. The results showed that moisture in clothing under $85 \% \mathrm{RH}$ significantly reduced subject mean skin temperatures(MST) and increased the local blood flow, due to enhanced heat loss by 
vapour evaporation. The initial skin wettedness was approximately 0.7 at $85 \% \mathrm{RH}$ and stabilised at 0.33 after $90 \mathrm{~min}$ exposure. The skin heat loss ( $\left.\mathrm{Q}_{\text {skin }}\right)$ at $85 \% \mathrm{RH}$ was almost twice as high as that at $15 \% \mathrm{RH}$ under the same temperature conditions, owing to larger sensible and evaporative heat loss caused by moist clothing. The inner clothing effective temperature $\mathrm{T}_{\text {eff }}$ was proposed to relate to TSV that the TSV increased by 1.12 units with an increase of $1{ }^{\circ} \mathrm{C}$ of $\mathrm{T}_{\text {eff, }}$, which quantified the coupled effects of air temperature and humidity in clothing microenvironment on human thermal comfort. The findings address the negative effect of clothing absorbing a large amount of moisture, which should be considered for indoor heating temperature designs in coldhumid environments.

\section{Keywords:}

Cold environment; Moisture in clothing; Physiological responses; Inner clothing effective temperature; Thermal comfort.

\section{Introduction}

Clothing provides a means of controlling heat exchange with the environment and is used outside the skin to extend the body's range of thermoregulatory control [1]. Particularly in cold climates, people are accustomed to clothing adjustments to adapt to the indoor and outdoor environments [2]. However, if the clothing allows for easy sorption of moisture, it may lead to certain additional chilled feelings under cold conditions. This phenomenon, known as "after chill", may be uncomfortable to the wearers [3]. Therefore, it is crucial to explore the effects caused by moisture in clothing on human thermal comfort in cold conditions.

Clothing adjustment, as a significant behavioural adaptation [4], reduces the metabolic heat generation when a body is outside of its thermos-neutral zone. To date, numerous on-site field surveys among different populations and ages [5-8] have explored the characteristics of occupant clothing regulations and highlighted the significant relations between clothing insulation and indoor/outdoor temperatures [911]. Based on an investigation in five cities of Pakistan, Nicol et al. [12] constructed a regression model of the changes in the mean clothing insulation, where the daily mean outdoor temperatures explained $80 \%$ of the changes in occupant clothing insulation. Several other developed models, such as the linear function $[11,13]$, power function [10], and exponential function [14], have also demonstrated improved fittings of the relations between clothing insulation and indoor and outdoor temperatures. Recently, Liu et al. [15] further proposed a logistic function to describe the relation between indoor clothing insulation and the running mean outdoor temperature, with the aim of 
reflecting the diminished degree of freedom for clothing adjustment with outdoor temperatures becoming high in summer and low in winter. All of these studies have addressed the important role of clothing regulations on human thermal comfort.

Nevertheless, owing to the limitations of population-based field surveys, the impact of moisture absorption and desorption in clothing on human thermal comfort has received little attention. Several researchers examining human perspiration absorption and desorption in clothing reported that skin wettedness was related to human heat exchanges and thermal comfort. As sweating always occurs and reacts with clothing in hot conditions, the moisture content, surface temperature and humidity, as well as the thermal/moisture transfer of clothing, are believed to affect the humanclothing microenvironments dramatically. Schneider [16, 17] presented a state-of-theart literature review on the moisture transfer through clothing and found that the changes in skin temperature were affected by the moisture sorption when in contact with the skin. The responses of skin thermoreceptors were found to be dependent on the skin temperature and its change rate, further determining the subjective feelings. Havenith et al. [18] examined clothing effects using the Predicted Mean Vote (PMV) model and pointed out that the PMV index did not include moisture vapour resistance in clothing; however, clothing with high vapour resistance would affect comfort owing to high skin wettedness, particularly outside the comfort zone. Nielson and Endrusick [19] studied the influence of subject physical activities and clothing structures on various thermal and moisture sensations. They determined that the skin wettedness contributed to humidity sensation, while dampness sensation was related to the amount of sweat accumulated in the clothing. By performing a series of experiments with clothed young females, Takanokura et al. [20] examined the influence of clothing moisture adsorption on the thermal sensation; the results indicated that subjects at rest were maintained in a thermal comfort state until the skin wettedness reached 0.25 to 0.3. These findings demonstrate that moisture in clothing contributes significantly to skin wettedness and therefore to comfort perceptions during actual wear conditions[2123]. Given the significance of moisture in clothing, the clothing vapour resistance has been included in the developed evaluation indices of Effective Temperature (ET*) and Standard Effective Temperature (SET), in which comfort is affected by heat loss at the skin, skin temperatures and skin wettedness [18]. However, although these indices reflect the heat and moisture transfer through clothing systems, they have mainly focused on warm and hot situations in which body sweat is a main driver affecting moisture in clothing, and little attention has been paid to the moisture absorption in clothing itself in cold-humid conditions. For example, people in Hot Summer and Cold Winter (HSCW) zone express significantly stronger cold feelings and unacceptability to cold-humid environments in reality in winter than those in northern China with a cold-dry climate. The clothing adjustment was more obvious in this zone than in cold zones [24], which is inferred to be owing to clothing thermal insulation performance in 
humid conditions. As a result, there remains a paucity of examining the effects of moisture in clothing on human comfort with high air humidity in cold climates.

It is hypothesized that higher air humidity produces external moisture contents in clothing, when people are trapped in ensembles, moisture may strongly affect the heat transfer by altering the thermal properties of clothes such as the thermal and vapour resistance. Several mechanisms of water vapour and liquid water transfer through clothing and textile materials have been explored [25]. Fan et al. [26] compared clothing thermal insulation under very low and very high perspiration, and found that clothing thermal insulation was reduced during perspiration and the amount varied from $2 \%$ to $8 \%$, depending on the water accumulation within the clothing ensembles. The effects of moisture on the thermal performance of multi-layer clothing assembly were analysed by Schacher [27] under low-level (6.3 to $\left.21 \mathrm{~kW} / \mathrm{m}^{2}\right)$ radiant heat exposure. It was observed that the thermal protective performance of clothing decreased for moist clothing, to which a lower amount (12\% to 50\%) of moisture was added. These results verify that moisture absorption and transfer through clothing strongly affects the heat transfer, by means of evaporation, condensation, desorption and absorption [28]. However, differing in objectives and disciplines, most of these previous studies were based on experimental measurements [29, 30] and numerical simulations [31, 32], focusing on clothing performance evaluation in specific situations. In that case, dynamic moisture absorption and desorption in clothing from ambient environments and their effects on heat transfer during wearing, as well as the comfort effects on wearers, remain incompletely understood.

Taken together, in cold-humid climates in winter, both moist clothing and high air humidity have profound effects on clothing performance and human thermal comfort. However, what are the thermal behaviours in the clothing microenvironment under actual wearing situations, and how to evaluate the clothing moisture effects caused by cold-humid environments on human thermal comfort remain unknown. Therefore, the study raises this research question from an investigation of the significantly colder feelings of people in the cold-humid climate (e.g., HSCW zone) in winter. This work payed attention to the possible moisture absorption and desorption effects in clothing and simulated a series of wearing trials in cold-humid and cold-dry environments. The dynamic changes of clothing microenvironments during dressing with pre-set water saturation in clothing were investigated, and the transient effects on physiological and psychological responses of human were evaluated. The outcome is expected to fill the gap in understanding the impact of transient thermal and moisture transfer in the clothing system on human thermal responses, and provide a consideration for improved heating design for indoor thermal environments in HSCW region in winter. 


\section{Methods}

\subsection{Climate chamber}

The experiments were carried out in a climate chamber with dimensions of $4 \times 3 \times 3 \mathrm{~m}(\mathrm{~L} \times \mathrm{W} \times \mathrm{H})$. The air temperature and humidity in the chamber could be effectively controlled. The air temperature could be regulated within the range of $-5{ }^{\circ} \mathrm{C}$ to $40{ }^{\circ} \mathrm{C}$, with an accuracy of $\pm 0.3{ }^{\circ} \mathrm{C}\left(<10{ }^{\circ} \mathrm{C}, \pm 0.5{ }^{\circ} \mathrm{C}\right)$. The chamber could be modified with relative humidity $(\mathrm{RH})$ by automatically controlling the input power of the wheel dehumidifier and steam humidifier, within the range from $0 \%$ to $100 \%$ and with an accuracy of $\pm 3 \%$. The air during the experiments was supplied to the chamber using piston flow ventilation through the perforated ceiling and the air velocity in the chamber was controlled under $0.1 \mathrm{~m} / \mathrm{s}$. A room adjacent to the chamber was maintained at a neutral thermal environment $\left(26{ }^{\circ} \mathrm{C}, 50 \%-60 \% \mathrm{RH}\right)$ for preparation work prior to the experiments.

\subsection{Experimental design}

\subsubsection{Experimental conditions}

The research is derived from the question that people in HSCW zone commonly express colder feelings during winter and attribute it to high air humidity in this region. Reference [9] addressed the typically cold and humid climate during winter in HSCW zone that with no heating, both the indoor and outdoor RH were generally over $70 \%$. In contrast, in the north of China, the RH was relatively low; coupled with a long indoor heating period, the RH was lower than 30\% [33]. This provided a research background for the experimental design in this study.

With one previous study, Li et al. [34] had designed a series of experiments in spring, summer and winter to examine human thermal responses under a wide range of $\mathrm{RH}$ levels, which based on the meteorological data in Chongqing, China. This study referred to the previous experimental design and selected the $85 \% \mathrm{RH}$ level as a fundamental research, considering the limited exposure duration in the tests, rather than long-term exposure. Meanwhile, a substantially lower 15\% RH was selected to conduct a comparison. Furthermore, because the experiments were designed to simulate winter scenarios, the temperature conditions were determined for cold sides, based on the calculated PMV at cold (PMV < - 1), moderately cold (-1 < PMV <-0.5), and neutral ($0.5<\mathrm{PMV}<0$ ). Table 1 displays the design conditions during the experiments, as well as the corresponding humidity ratio, where significantly differences can be observed between the $15 \% \mathrm{RH}$ and $85 \% \mathrm{RH}$ conditions. 
Table 1 Design conditions for experiments

\begin{tabular}{cccc}
\hline Condition & Temperature $\left({ }^{\circ} \mathrm{C}\right)$ & $\mathrm{RH}(\%)$ & Humidity ratio $(\mathrm{g} / \mathrm{kg})$ \\
\hline 1 & 16 & 15 & 1.7 \\
2 & 16 & 85 & 9.7 \\
3 & 20 & 15 & 2.1 \\
4 & 20 & 85 & 12.5 \\
5 & 24 & 15 & 2.7 \\
6 & 24 & 85 & 16.1 \\
\hline
\end{tabular}

\subsubsection{Experimental clothing}

It is hypothesised that clothing performance may play a vital role in heat and moisture transfer in the human-clothing microenvironment system and lead to differences in human thermal perceptions in cold-humid and cold-dry environments. Cotton material has been confirmed to exhibit superior moisture absorption and desorption [35]. Therefore, this study selected clothing ensembles of $100 \%$ cotton, including a long-sleeved dress shirt, long-sleeved sweater shirt and thick trousers. A slightly thin clothing design compared to the previous study [33] was selected in this study. The net weight of the dried clothing ensembles was $1086 \mathrm{~g}$ in total (long-sleeved shirt: $190 \mathrm{~g}$, long-sleeved sweater: $423 \mathrm{~g}$, thick trousers: $473 \mathrm{~g}$ ). According to the ASHRAE Handbook[36], coupled with the underwear and shoes, the intrinsic clothing insulation of these ensembles was estimated at 0.9 clo.

Prior to each test, the clothes were pre-treated under the designed conditions (Table 1 ) in the climate chamber for at least $24 \mathrm{~h}$ to achieve a steady state balance of moisture in clothes. The initial moisture contents of the experimental clothes were calculated by weighing the clothes in dried and actual conditions, with each measurement repeated three times. Table 2 shows the mean weight of the experimental clothes in each condition at the beginning of tests. It is clearly observed that, compared to the dried weight of the clothes (approximately $1086 \mathrm{~g}$ ), after being placed under a highly humid condition $(85 \% \mathrm{RH})$ for a lengthly period, the clothing mass increased significantly. The calculated regain rates of the clothes in Table 1 were approximately $3 \%$ to $5 \%$ for $15 \% \mathrm{RH}$ and $8 \%$ to $11 \%$ for $85 \% \mathrm{RH}$, which is consistent with Morton [37], in which the regain rates of cotton were measured to be approximately $3 \%$ at $15 \% \mathrm{RH}$ and $10 \%$ at $85 \% \mathrm{RH}$. This ensured that the experimental clothes reached the moisture equilibrium between the clothing and environments under the designed conditions. The moisture differences in the clothing were attributed to the different humidity ratios in air under varying conditions, as indicated in Table 1 . These results respond to the research 
hypothesis of this study and lay the foundation for exploring the impacts of moisture in clothing on human thermal comfort.

Table 2 Changes in experimental clothes mass $(\text { mean } \pm \mathrm{SD})^{*}$

\begin{tabular}{cccccccc}
\hline \multirow{2}{*}{ Conditions } & \multicolumn{2}{c}{16} & \multicolumn{2}{c}{20} & \multicolumn{2}{c}{24} \\
& $15 \%$ & $85 \%$ & $15 \%$ & $85 \%$ & $15 \%$ & $85 \%$ \\
\hline Before & $1091 \mathrm{~g} \pm$ & $1190 \mathrm{~g} \pm$ & $1090 \mathrm{~g} \pm$ & $1215 \mathrm{~g} \pm$ & $1090 \mathrm{~g} \pm$ & $1231 \mathrm{~g} \pm$ \\
experiments & $24 \mathrm{~g}$ & $72 \mathrm{~g}$ & $69 \mathrm{~g}$ & $70 \mathrm{~g}$ & $69 \mathrm{~g}$ & $77 \mathrm{~g}$ \\
Regain rate $^{* *}$ & $5.30 \%$ & $8.70 \%$ & $3.00 \%$ & $10.60 \%$ & $3.80 \%$ & $11.80 \%$ \\
\hline
\end{tabular}

Note: * the clothes mass was averaged by all 20 tests (i.e., 20 subjects) in each condition.

**: the clothing regain rate was calculated as follows: $\mathrm{R}=\left(\mathrm{W}_{\text {actual }}-\mathrm{W}_{\text {dry }}\right) / \mathrm{W}_{\text {dry }} * 100 \%$

where $\mathrm{W}_{\text {actual }}$ is the weight of experimental clothes at steady state under designed conditions, $\mathrm{g} ; \mathrm{W}_{\text {dry }}$ is the weight of experiment clothes at dried condition.

\subsection{Subjects}

A priori power analysis in $\mathrm{G}^{*}$ Power 3[38] was employed to calculate the appropriate sample size according to experimental design. The within-subject design was used to minimise individual differences. Refering to [39], the test type was the Ftest and the statistical test was ANOVA (repeated measures, within factors: power level $1-\beta(0.8)$, significance level $\alpha(0.05)$, effect size $f(0.4)$ ). The calculated sample size was 16 for each condition. During recruiting, the body mass index was firstly controlled within a narrow range to minimise the metabolic rate differences. The subjects were required to be in cold-humid climates (for example, Chongqing) for more than one year and in good health, with no cold-related sensitivity. A total of 20 subjects (10 females and 10 males, all university students) were finally recruited and paid to participate in the experiments.

The experiments were performed in accordance with the ethical standards of the 1964 Declaration of Helsinki [40]. Written content regarding the study was received from subjects before they participated in the experiments. At the first time subjects visited the laboratory, they were provided further details in order to become acquainted with the experimental procedure, relevant instruments, physiological measurements. Prior to each test, the participants were asked not to drink alcohol, do strenuous exercise, or smoke, as well as to refrain from drinking coffee and tea for $2 \mathrm{~h}$ before the test. The anthropometric data from the subjects are displayed in Table 3. 
Table 3 Physical characteristics of subjects (mean $\pm \mathrm{SD}$ )

\begin{tabular}{ccccccc}
\hline Sex & Number & Age $($ year $)$ & Height $(\mathrm{cm})$ & Weight $(\mathrm{kg})$ & $\mathrm{A}_{\mathrm{D}}\left(\mathrm{m}^{2}\right)$ & Clo \\
\hline Male & 10 & $22.7 \pm 0.8$ & $175 \pm 6$ & $64.5 \pm 6.1$ & $1.78 \pm 0.1$ & 0.9 \\
Female & 10 & $23.2 \pm 0.6$ & $163 \pm 4$ & $52.7 \pm 5.9$ & $1.55 \pm 0.1$ & 0.9 \\
Total & 20 & $22.9 \pm 0.8$ & $169 \pm 7$ & $60.4 \pm 9.0$ & $1.66 \pm 0.1$ & 0.9 \\
\hline
\end{tabular}

\subsection{Instruments and measurements}

The ambient air temperature and $\mathrm{RH}$ in the climate chamber were monitored continuously by means of a thermal comfort monitoring instrument (MI 6401). The sensors were placed in the centre of the chamber near to the subjects at a $0.6 \mathrm{~m}$ height and the data were recorded every $10 \mathrm{~s}$.

The subjects' local skin temperatures on eight parts of the body, including the forehead, left chest, left back, left upper arm, left lower arm, left hand, right anterior thigh and anterior calf, were measured by thermocouples (TSD202B, BIOPAC). The data were recorded at $10 \mathrm{~s}$ intervals by the multi-channel physiological acquisition system (MP150). The mean skin temperature (MST) were calculated using an eightpoint formula[41], based on the area-weighted averages of the local skin temperatures, as expressed in Equation (1). Moreover, a study by Berglund et al. [42] indicated that the dew point gradient in the gap between the skin and clothing is small, so the vapour pressure measurement close to the skin can be used to estimate the vapour pressure at the skin surface. Therefore, the air temperature $\left(\mathrm{T}_{\mathrm{in}}\right)$ and relative humidity $\left(\mathrm{RH}_{\text {in }}\right)$ in the clothing microenvironment between the subject skin surfaces and inner clothing layers were monitored by means of wireless thermal sensors (PyroButton-TH, Opulus), at the same four locations as the measured local skin temperatures, namely the chest, upper arm, thigh and calf. The mean $\mathrm{T}_{\text {in }}$ and $\mathrm{RH}_{\text {in }}$ values were calculated by the four-point weight method ( 0.3 for chest and upper arm, 0.2 for thigh and calf). The vapour pressure between the skin and inner clothes was calculated by using $\mathrm{T}_{\text {in }}$ and $\mathrm{RH}_{\text {in }}$ based on the ASHRAE Handbook[36], and the mean value $\left(\mathrm{P}_{\mathrm{sk}}\right)$ was calculated by Equation (2).

$$
\begin{aligned}
\text { MST }= & 0.07 * \mathrm{~T}_{\text {forehead }}+0.175 * \mathrm{~T}_{\text {chest }}+0.175 * \mathrm{~T}_{\text {back }}+0.07 * \mathrm{~T}_{\text {upperarm }} \\
& 0.07 * \mathrm{~T}_{\text {lowerarm }}+0.05 * \mathrm{~T}_{\text {hand }}+0.19 \mathrm{~T}_{\text {thigh }}+0.2 * \mathrm{~T}_{\text {calf }} \\
\mathrm{P}_{\text {sk }}= & 0.3 * \mathrm{P}_{\text {sk, chest }}+0.3 * \mathrm{P}_{\text {sk,arm }}+0.2 * \mathrm{P}_{\text {sk,thigh }}+0.2 * \mathrm{P}_{\text {sk,calf }}
\end{aligned}
$$

The local blood flow at the back of the left hand of the subjects was measured using the Laser Doppler probe (MP150-LDF100C), with a time interval of $10 \mathrm{~s}$. Before and after each test, the clothing ensembles and subjects with and without clothes were weighed (YP100KN), in order to calculate the mass loss of the body and clothes.

The details of the instruments used in experiments are summarized in Table 4. 
Table 4 Measuring parameters and instruments during experiments

\begin{tabular}{|c|c|c|c|}
\hline Measured indices & Instrument & Place & Range and accuracy \\
\hline $\begin{array}{l}\text { Environmental } \mathrm{T}_{\mathrm{a}} \\
\text { and } \mathrm{RH}\end{array}$ & $\begin{array}{l}\text { Thermal comfort monitoring } \\
\text { instrument MI } 6401\end{array}$ & $\begin{array}{c}\text { METREL, } \\
\text { Germany }\end{array}$ & $\begin{array}{c}\text { Accuracy: } \mathrm{T}: \pm 0.2^{\circ} \mathrm{C} \text {, relative } \\
\text { humidity: } \pm 2 \%\end{array}$ \\
\hline $\begin{array}{l}\text { Local skin } \\
\text { temperature }\end{array}$ & $\begin{array}{c}\text { Sensor: TSD202B } \\
\text { Logger: MP150-SKT100C }\end{array}$ & BIOPAC, US & $0{ }^{\circ} \mathrm{C}-70{ }^{\circ} \mathrm{C}$, accuracy: $\pm 0.1^{\circ} \mathrm{C}$ \\
\hline $\begin{array}{l}\text { Clothing } \\
\text { microenvironment }\end{array}$ & PyroButton-TH & Opulus, US & $\begin{array}{c}-20^{\circ} \mathrm{C}-+85^{\circ} \mathrm{C}, \text { accuracy: } \\
\pm 0.1^{\circ} \mathrm{C} \text { (calibrated), resolution: }\end{array}$ \\
\hline $\mathrm{T}_{\text {in }}$ & & & $0.0625^{\circ} \mathrm{C}$ \\
\hline $\begin{array}{c}\text { Clothing } \\
\text { microenvironment } \\
\mathrm{RH}_{\mathrm{in}}\end{array}$ & PyroButton-TH & Opulus, US & $\begin{array}{c}0 \%-100 \% \text {, accuracy: } \pm 1 \%(10 \%- \\
90 \%) \text {, resolution: } 0.4 \%\end{array}$ \\
\hline Blood flow & $\begin{array}{l}\text { Sensor: Laser Doppler probe } \\
\text { Logger: MP150-LDF100C }\end{array}$ & $\begin{array}{c}\text { BIOPAC } \\
\text { Company, US }\end{array}$ & l \\
\hline Body weight & YP100KN & Japan & Accuracy: $\pm 1 \mathrm{~g}$ \\
\hline
\end{tabular}

A questionnaire was designed to investigate the subjective thermal perceptions. The thermal sensation was evaluated based on ASHRAE 55[43] seven-point scale (-3: cold, -2: cool, -1: slightly cool, 0 : neutral, +1 : slightly warm, +2 : warm, +3 hot) Subjects' sensation to air humidity was referred to the evaluation of wettedness sensation $[44,45]$, but with a slightly fine-tuned description and scale. That is, the study defined the humidity sensation and adopted the seven-point bipolar scale instead of the seven-point unipolar scale (-3: very dry, -2: dry, -1: slightly dry, 0: neutral, +1: slightly humid, +2: humid, +3: very humid), which is consistent with [34]. In addition, subjects reported their thermal/humidity acceptability on a split scale with a gap in the middle, from clearly unacceptable $(-1)$ to slightly unacceptable $(-0.1)$, and thereafter from slightly acceptable $(+0.1)$ to clearly acceptable $(+1)$. The subjects were also given the option to score 0.5 with all scales if they hesitated to select between adjacent scales (e.g., +1.5 between +1 and +2 ) when filling in the questionnaires.

\subsection{Experimental process}

The experiments were conducted during winter from December 2016 to January 2017, in Chongqing, China. Each subject participated in all six experimental conditions, and each time two subjects were simultaneously arranged in a test.

For each test, the climate chamber was pre-set to the designed conditions $1 \mathrm{~h}$ in advance to ensure a uniform environment. Subjects were asked to arrive at the chamber $30 \mathrm{~min}$ in advance to eliminate the effects of outdoor environments and individual metabolisms. During preparation, the subjects were dressed in experimental clothing ensembles with pre-set moisture. They were asked to weigh their body mass, single 
clothing mass and fully dressed mass. Thereafter, subjects were asked to attach the thermocouples onto the local skin surfaces (see section 2.4) using surgical, water permeable, and adhesive tapes. Then, the back sides of PyroButton sensors (Figure 1(d)) were attached to subjects' inner clothing layers in four places using double-sided adhesive tape, responding to the locations of measured skin temperatures. In that case, the front measurement sides with temperature and relative humidity sensors (see Figure 1(d)) were closely oriented to skin surface to measure the microenvironment. The backs of the left hand of the subjects were cleaned using an alcohol preparation pad, following which the Laser Doppler probe was fixed at the back using medical adhesive tape (Figure 1(a) and (b)). All of these preparations were carried out in the chamber to avoid the effects of outdoor environments. For the first time, the subjects were briefed regarding the questionnaire contents and evaluation scale of each index. For example, the meanings of the seven-scale thermal sensation and humidity sensation votes were explained with an additional understanding based on ASHRAE 55[43]: the environmental temperature and humidity were acceptable if they voted sensations from -1 to +1 , and were not acceptable if they voted beyond this range. This ensured they were well-informed on the questionnaires and voted correctly based on their subjective perceptions.

The formal test lasted for 90 min, starting after the subjects finished all of the preparations. Over this period, the environmental parameters and subject physiological indices were measured continuously. Besides, subjects rated their thermal perceptions every $5 \mathrm{~min}$ at the first $30 \mathrm{~min}$ and every $10 \mathrm{~min}$ thereafter throughout the test, using identical questionnaires. Subjects were occupied with office work, and only light activities such as reading, listening and talking softly were allowed in order to maintain a steady state condition (the metabolic rate was 1.0 met [43]). The on-site measurement is illustrated in Figure1.

At the end of the tests, the subjects were asked to change their clothes and weigh again, the requirements being the same as those before the test. The test was then completed once all data were collected and saved. The experimental process was repeated for all six conditions. 


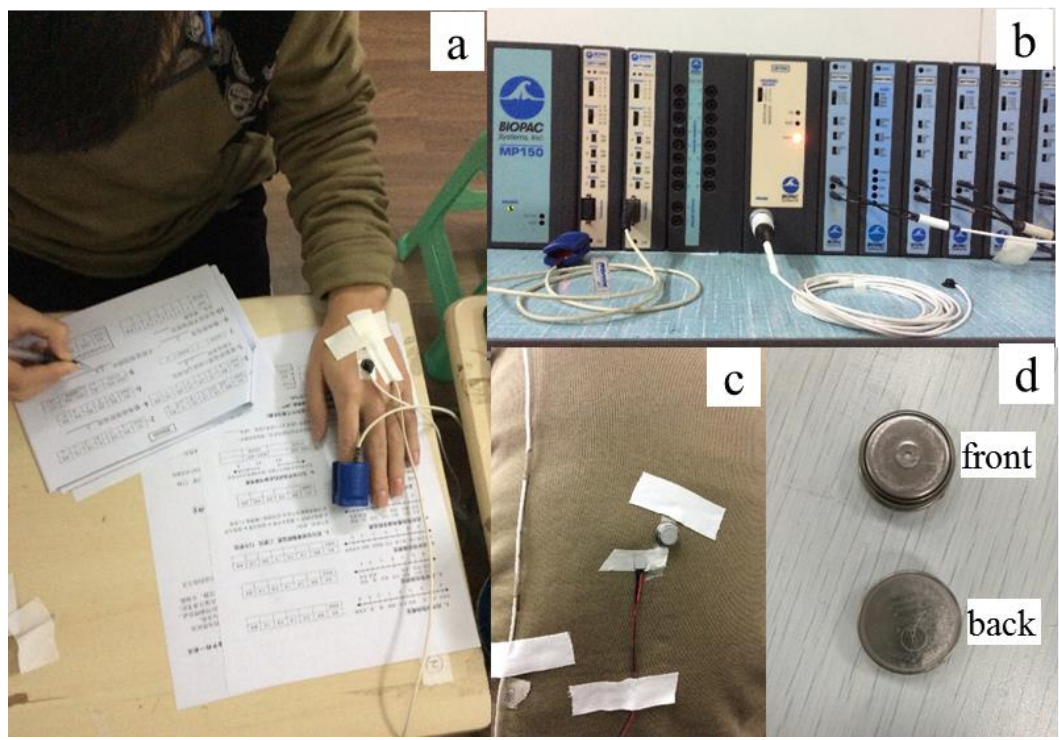

Figure 1 On-site measurement during experiments. (a) skin blood flow at back of hand (b) MP150 multi-channel physiological acquisition system (c) clothing microenvironment measurement on back (d) PyroButton-TH sensor.

Note:

1) the blood oxygen saturation $(\mathrm{SpO} 2)$ was meantime measured in Figure 1 (a) (fingertip measurement) and the heat flux on clothing surface at some local parts of body were measured in Figure 1(c), but exclusively analyzed in this study;

2) the measurement of outer layer of clothes was displayed as example in Figure 1(c) considering it was difficult to take pictures of sensors in the inner layer of clothes when wearing.

3) the back of PyroButton in Figure 1(d) was attached to the inner clothing layer of subjects to ensure the front side with temperature and humidity sensors orienting to skin surface to measure the clothing microenvironment.

\subsection{Date processing}

\subsubsection{Statistical analysis}

The mean values for physiological parameters and questionnaires from all 20 subjects were used, whatever for steady state condition, or for transient condition. For steady state condition, the repeated ANOVA was performed to determine the stable time and then the values at steady state were averaged. For transient condition, the parameters recorded at $10 \mathrm{~s}$ interval during experiments were averaged at $1 \mathrm{~min}$ interval during analysis for each subject. The dynamic results over 90min were presented by averaging the values of 20 subjects at each minute. The Shapiro-Wilk W-test was used to test the normality of the distribution for all metrics and the ANOVA test was then used to compare the differences caused by air temperature and humidity. The correlations among the subjective votes and physiological indices were analysed using linear/non-linear regression. A significance level of 0.05 was applied throughout the 
analysis.

\subsubsection{Body heat loss}

It is estimated that approximately $97 \%$ of body heat production is dissipated by radiation, convection and evaporation at skin surface, and $3 \%$ by means of respiration [46]. Therefore, heat exchanges between the body skin surface and environment affect human thermal sensation. In order to evaluate such effects quantitatively, the Gagge' [47] two-node physiological model was employed to obtain the theoretical heat loss from skin surface $\left(\mathrm{Q}_{\text {skin }}\right)$.

In addition, a method using the heat balance equation in ASHRAE Handbook[36] was used, to calculate the real $\mathrm{Q}_{\text {skin }}$ according to experimental design in this study, as indicated in Equation(3).

$$
\begin{aligned}
\mathrm{Q}_{\mathrm{skin}} & =\mathrm{C}+\mathrm{R}+\mathrm{E}_{\mathrm{sk}} \\
& =\left(\mathrm{t}_{\mathrm{sk}}-\mathrm{t}_{\mathrm{o}}\right) /\left[\mathrm{R}_{\mathrm{cl}}+1 /\left(\mathrm{f}_{\mathrm{cl}} \mathrm{h}\right)\right]+\mathrm{w}\left(\mathrm{p}_{\mathrm{sk}, \mathrm{s}}-\mathrm{p}_{\mathrm{a}}\right) /\left[\mathrm{R}_{\mathrm{e}, \mathrm{cl}}+1 /\left(\mathrm{f}_{\mathrm{cl}} \mathrm{h}_{\mathrm{e}}\right)\right]
\end{aligned}
$$

where $\mathrm{Q}_{\text {skin }}$ is the total heat loss, $\mathrm{W} / \mathrm{m}^{2}$; $\mathrm{C}$ is the convective heat loss from the skin surface, $\mathrm{W} / \mathrm{m}^{2}$; $\mathrm{R}$ the radiant heat loss from the skin surface, $\mathrm{W} / \mathrm{m}^{2} ; \mathrm{E}_{\mathrm{sk}}$ is the evaporative heat loss from the skin surface, $\mathrm{W} / \mathrm{m}^{2} ; \mathrm{t}_{\mathrm{sk}}$ is the skin temperature, ${ }^{\circ} \mathrm{C} ; \mathrm{t}_{\mathrm{o}}$ is the ambient operative temperature, ${ }^{\circ} \mathrm{C} ; \mathrm{R}_{\mathrm{cl}}$ is the thermal resistance of clothing, $\mathrm{m}^{2} \mathrm{~K} / \mathrm{W}$; $\mathrm{f}_{\mathrm{cl}}$ is the clothing area factor; $\mathrm{h}$ is the total convective and radiative heat transfer coefficient, $\mathrm{W} / \mathrm{m}^{2}{ }^{\circ} \mathrm{C}$; $\mathrm{w}$ is the skin wettedness; $\mathrm{p}_{\mathrm{sk}, \mathrm{s}}$ is the saturated water vapour pressure at skin temperature $\left(t_{\mathrm{sk}}\right), \mathrm{kPa} ; \mathrm{R}_{\mathrm{e}, \mathrm{cl}}$ is the evaporative heat transfer resistance of clothing, $\mathrm{m}^{2} \mathrm{~Pa} / \mathrm{W}$; and $\mathrm{h}_{\mathrm{e}}$ is the evaporative heat transfer coefficient, $\mathrm{W} / \mathrm{m}^{2} \mathrm{kPa}$.

Because the moisture absorption and desorption in clothing ensembles is a dynamic process when worn by people, the thermal and moisture vapour resistances will certainly change with the time and remained moisture contents in clothes. However, it is indeed difficult to predict the thermal and vapour resistance dynamically, which is dependent on the microenvironment of the skin-clothing system. As the aim of this study is to evaluate the relative variations in skin heat loss among different conditions and between experimental and theoretical values, the intrinsic thermal resistance and vapor resistance of the clothing ensembles are used in Equation (3) [43]. Using such prerequisites, several calculating parameters in Equation (3) [36] are determined in Table 5. The comparisons using two methods to calculate the $\mathrm{Q}_{\text {skin }}$ are analysed in the following Results section.

Table 5 Calculation values of parameters in Equation (3)

\begin{tabular}{cccccc}
\hline Parameter & Value & Unit & Parameter & Value & Unit \\
\hline $\mathrm{I}_{\mathrm{cl}}$ & 0.9 & clo & $\mathrm{h}_{\mathrm{c}}$ & 3.1 & $\mathrm{~W} / \mathrm{m}^{2}{ }^{\circ} \mathrm{C}$ \\
$\mathrm{R}_{\mathrm{cl}}$ & 0.1395 & $\mathrm{~m}^{2 \circ} \mathrm{C} / \mathrm{W}$ & $\mathrm{h}_{\mathrm{r}}$ & 4.7 & $\mathrm{~W} / \mathrm{m}^{2}{ }^{\circ} \mathrm{C}$ \\
$\mathrm{f}_{\mathrm{cl}}$ & 1.279 & $/$ & $\mathrm{h}$ & 7.8 & $\mathrm{~W} / \mathrm{m}^{2}{ }^{\circ} \mathrm{C}$
\end{tabular}




\begin{tabular}{rccccc}
$\mathrm{i}_{\mathrm{m}}$ & 0.38 & $/$ & $\mathrm{h}_{\mathrm{e}}$ & 51.15 & $\mathrm{~W} / \mathrm{m}^{2} \mathrm{kPa}$ \\
$\mathrm{LR}$ & 16.5 & ${ }^{\circ} \mathrm{C} / \mathrm{kPa}$ & $\mathrm{R}_{\mathrm{e}, \mathrm{cl}}$ & 0.0223 & $\mathrm{~m}^{2} \mathrm{kPa} / \mathrm{W}$ \\
\hline
\end{tabular}

\subsubsection{Inner clothing effective temperature, $\mathrm{T}_{\text {eff }}$}

The skin temperature has been illustrated as providing the potential to predict human thermal comfort at a steady state [48, 49], but only the heat and mass exchanges between the skin surfaces and environments through clothing systems have been considered. In this case, the clothing is defined as being the intermediary function, and the potential additional heat loss from the human body resulting from moisture vaporisation in clothing is neglected to a significant extent. Therefore, this study initially focused on the moisture in clothing. Given that not only the air temperature, but also the relative humidity in the clothing microenvironment affect significantly the body physiological responses and thermal comfort, we adopted the index "inner clothing effective temperature ( $\left.T_{\text {eff }}\right)$ " to evaluate the coupled effect, which is defined by Equations(4) and (5) [50].

$$
\begin{array}{r}
\mathrm{T}_{\text {eff }}=0.492 * \mathrm{~T}_{\text {in }}+0.19 * \mathrm{P}_{\text {in }}+6.47 \\
\mathrm{P}_{\text {in }}=0.6107 * \exp \left(\left(17.27 * \mathrm{~T}_{\text {in }}\right) /\left(237.3+\mathrm{T}_{\text {in }}\right)\right) * \mathrm{RH}_{\text {in }}
\end{array}
$$

where $\mathrm{T}_{\text {eff }}$ is the effective temperature, ${ }^{\circ} \mathrm{C}$; $\mathrm{T}_{\text {in }}$ is the inner clothing temperature, ${ }^{\circ} \mathrm{C} ; \mathrm{P}_{\text {in }}$ is the inner clothing water vapour pressure, $\mathrm{kPa}$; and $\mathrm{RH}_{\mathrm{in}}$ is the inner clothing relative humidity, $\%$.

The $\mathrm{T}_{\text {eff }}$ was related to subjects' thermal sensation votes (TSV) to quantify clothing moisture effects on thermal comfort in the following results. The real time $\mathrm{T}_{\text {eff }}$ of each subjects in minutes was calculated and then the mean values were obtained by 20 subjects. As the $T_{\text {eff }}$ were continuous variables and the TSV were discrete ones, the $T_{\text {eff }}$ was averaged in periods responding to when subjects voting their thermal sensations. Such data processing was used to examine the relation of $\mathrm{T}_{\text {eff }}$ and TSV and to reflect the transient changes of both during 90min in Results.

\section{Results}

\subsection{Clothing microenvironment}

\subsubsection{Water loss in experimental clothes}

The mass of the experimental clothes before and after each test was determined to explore the changes in moisture contents in clothes and the water loss is plotted in Figure 2 under different conditions. The water loss of the experimental clothes was significantly higher under 85\% RH (ANOVA, $\mathrm{p}<0.05$ ), increasing from $79 \mathrm{~g}$ at 16 
${ }^{\circ} \mathrm{C} / 85 \% \mathrm{RH}$ to $97 \mathrm{~g}$ at $24{ }^{\circ} \mathrm{C} / 85 \% \mathrm{RH}$. In contrast, little fluctuation was observed in the water loss at $15 \% \mathrm{RH}$, at lower than $10 \mathrm{~g}$. This was attributed to the differences of moisture absorption in the experimental clothes (Table 2: clothing weight) before experiments. Therefore, when subjects wore clothes with high moisture contents during the tests, the vapour evaporation caused by the clothes was inferred to promote additional heat loss from the body, inevitably affecting the thermal comfort of subjects in cold environments.

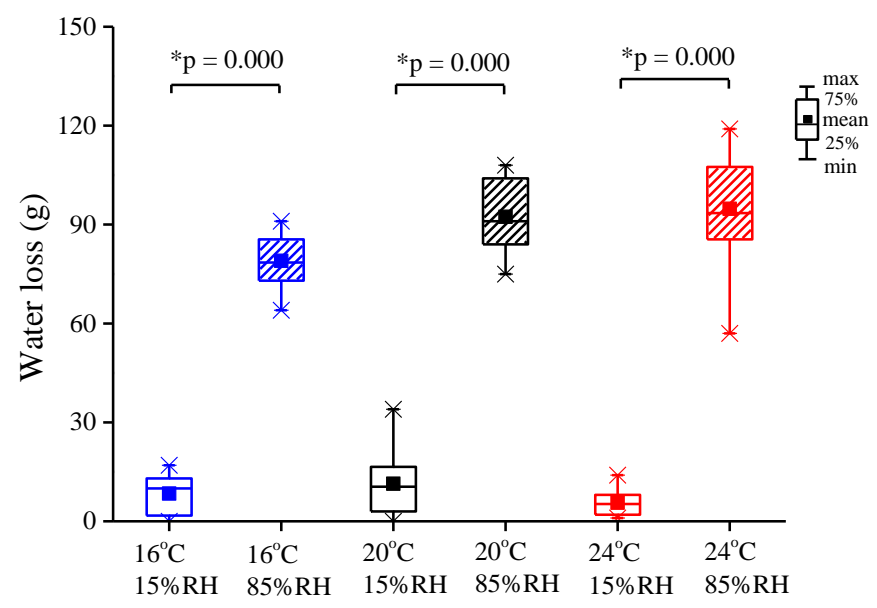

Figure 2 Water loss in clothes before and after experiments

\subsubsection{Inner clothing $\mathrm{T}_{\text {in }}$ and $\mathrm{RH}_{\text {in }}$}

The real time $\mathrm{T}_{\text {in }}$ and $\mathrm{RH}_{\mathrm{in}}$ values of the clothing microenvironment in minutes were calculated for each condition and the mean values were then obtained for 20 subjects. Figure 3 illustrates the mean $\mathrm{T}_{\text {in }}$ and $\mathrm{RH}_{\text {in }}$ between the skin and inner clothing microenvironment under six conditions. In Figure 3(a), the mean $\mathrm{T}_{\text {in }}$ exhibited consistent increases during the initial $30 \mathrm{~min}$ and stabilised thereafter under all six conditions. Moreover, higher ambient temperature resulted in higher mean $\mathrm{T}_{\mathrm{in}}$. However, for each temperature level, the mean $\mathrm{T}_{\text {in }}$ values were higher at $15 \% \mathrm{RH}$ compared to $85 \% \mathrm{RH}$, particularly at $16{ }^{\circ} \mathrm{C}$. For example, the mean values of $\mathrm{T}_{\text {in }}$ at 16 ${ }^{\circ} \mathrm{C} / 15 \%$ RH fluctuated within the range of $26{ }^{\circ} \mathrm{C}-28{ }^{\circ} \mathrm{C}$ while these values were $24{ }^{\circ} \mathrm{C}$ to $26{ }^{\circ} \mathrm{C}$ at $16{ }^{\circ} \mathrm{C} / 85 \% \mathrm{RH}$. This was inferred that the initial higher moisture contents of the experimental clothes under $85 \% \mathrm{RH}$ (Table 2) were evaporated during the experiments (Figure 2), thereby enhancing the heat loss from the body and reducing the inner air temperatures in the clothing microenvironment. 

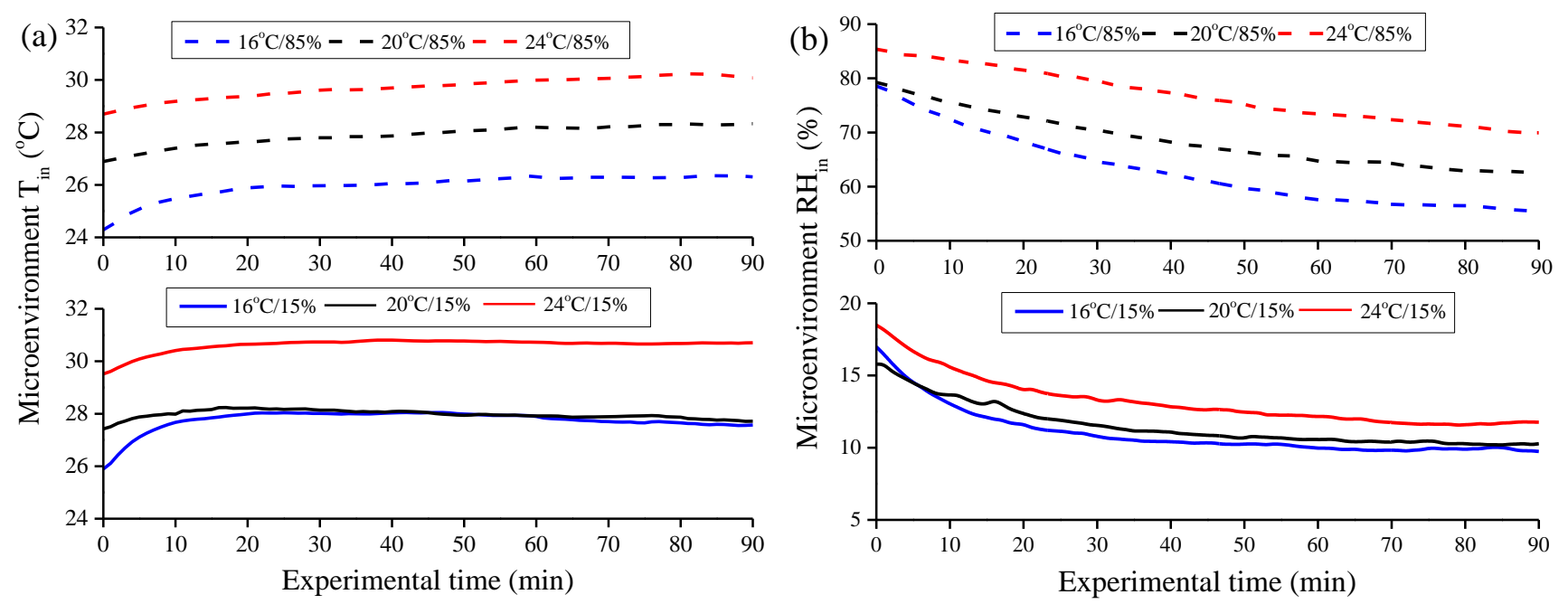

Figure 3 Changes in mean $\mathrm{T}_{\text {in }}$ and $\mathrm{RH}_{\text {in }}$ in inner clothing environment over time

Compared to Figure 3(a), the trends of the mean $\mathrm{RH}_{\text {in }}$ during the 90 min were opposite, as indicated in Figure 3(b). That is, the mean $\mathrm{RH}_{\text {in }}$ under both low and high humidity levels decreased gradually and then remained stable. The mean $\mathrm{RH}_{\text {in }}$ values decreased quickly from over $15 \%$ to approximately $10 \%$ at initial $30 \mathrm{~min}$ under $15 \%$ $\mathrm{RH}$, and the differences between the three temperature levels were small. In contrast, under $85 \% \mathrm{RH}$, a high $\mathrm{RH}_{\text {in }}$ was observed in the clothing microenvironment and the differences in $\mathrm{RH}_{\text {in }}$ among three temperature levels were significant over the whole process. The initial mean $\mathrm{RH}_{\text {in }}$ were nearly close to $80 \%$ under $16{ }^{\circ} \mathrm{C} / 85 \% \mathrm{RH}$ and 20 ${ }^{\circ} \mathrm{C} / 85 \% \mathrm{RH}$, and were reduced to approximately $55 \%$ and $60 \%$, a large $\mathrm{RH}$ differences being observed between the beginning and the end of tests. However, the initial $\mathrm{RH}_{\text {in }}$ at $24{ }^{\circ} \mathrm{C} / 85 \% \mathrm{RH}$ was even up to $85 \%$ but decreased slightly during experiments. In particular, the $\mathrm{RH}_{\text {in }}$ at $24^{\circ} \mathrm{C}$ in Figure 3(b) was the highest during the entire process and was not stable by the end of tests. This could partly be explained by the higher moisture absorption in clothes at $24{ }^{\circ} \mathrm{C} / 85 \% \mathrm{RH}$ at first (Table 2). Furthermore, with increasing relative humidity, the difference in water vapour pressure between the skin surfaces and ambient environments were lessen at $24{ }^{\circ} \mathrm{C} / 85 \% \mathrm{RH}$, which in turn reduced the evaporation rate of moisture contents in clothing. Coupled with a limited exposure time of 90min, the moisture in experimental clothes might not evaporate completely, thereby leading to higher $\mathrm{RH}_{\mathrm{in}}$ values at $24{ }^{\circ} \mathrm{C} / 85 \% \mathrm{RH}$, as illustrated in Figure 3 (b).

\subsection{Physiological responses}

\subsubsection{MST}

Figure 3 presents the changes in the clothing microenvironments, which were closely related to the subjects' skin temperatures. Therefore, Figure 4 further demonstrates the changes in MST for all 20 subjects at a steady state under the six 
conditions, which are distinguished by different colours and symbols. According to Figure 4, the MST of subjects increased with the temperatures (ANOVA, p < 0.05), from $32{ }^{\circ} \mathrm{C}$ at $16{ }^{\circ} \mathrm{C}$ to $32.4{ }^{\circ} \mathrm{C}$ at $24{ }^{\circ} \mathrm{C}$. Moreover, the RH significantly affected subjects' MST under the same temperature levels. The MST were obviously lower under $85 \%$ $\mathrm{RH}$, and significant differences were found between 15\% RH and 85\% RH (p<0.05), which were somewhat inconsistent with the theory predictions [51], without considering the moisture in clothing itself and the consequent evaporative heat loss.

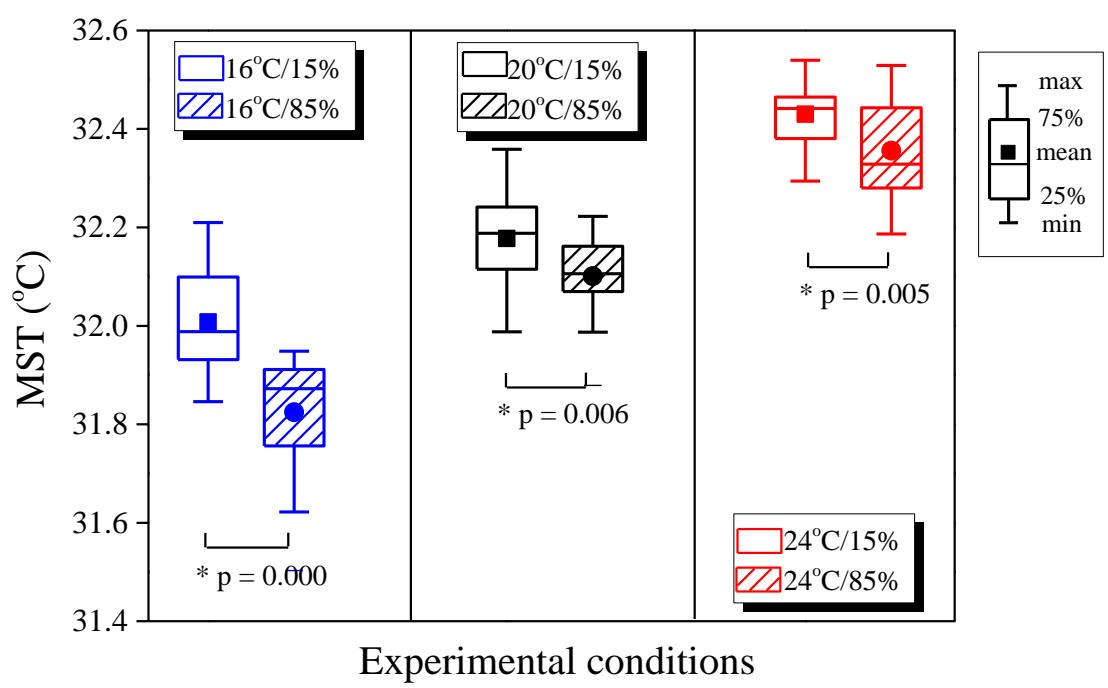

Figure 4 Changes in subjects' MST under different conditions

\subsubsection{Skin wettedness}

Skin wettedness has been recognised as one of the most convenient indices for predicting human comfort levels, especially for sweating conditions on the warm sides[18]. Thanks to the measured local skin temperatures, microenvironment $T_{\text {in }}$ and $\mathrm{RH}_{\text {in }}$ in clothing obtained by the sensors, the subject skin wettedness was calculated referring to the study of Berglund [52]. Figure 5 illustrates the changes of mean skin wettedness of 20 subjects in minutes during experiments. The gradual downward trends were observed under all conditions in Figure 5. For 15\% RH, the skin wettedness was approximately 0.12 at the initial stage and decreased to approximately 0.025 by the end of the experiments. Negligible differences existed for the three temperature levels, except that the skin wettedness was slightly higher at $16^{\circ} \mathrm{C}$. In contrast, the subject skin wettedness values were comparably higher under $85 \% \mathrm{RH}$, with a remarkable decrement between the beginning and ending of the experiments. For example, the skin wettedness was initially approximately 0.7 at $16{ }^{\circ} \mathrm{C} / 85 \% \mathrm{RH}$ and stabilised at 0.33 . Similar trends were observed under the other two conditions but the steady state was not reached under $20{ }^{\circ} \mathrm{C} / 85 \% \mathrm{RH}$, which was consistent with Figure 3. However, a converse change trend was found among the three temperature levels under $85 \% \mathrm{RH}$. 
Unlike the low humidity level (15\% RH) at which the skin wettedness of subjects at 16 ${ }^{\circ} \mathrm{C} / 85 \% \mathrm{RH}$ was higher, the skin wettedness of subjects at $24{ }^{\circ} \mathrm{C} / 85 \% \mathrm{RH}$ was slightly higher than that at $16^{\circ} \mathrm{C} / 85 \% \mathrm{RH}$. This was reasonably expected as the MST increased with the temperatures (Figure 4). In addition, the humidity ratio differences among varying temperature levels (Table 1) led to higher moisture absorption in clothes under a high temperature level (Figure 3(b)), thereby increasing the skin wettedness in Figure 5 .

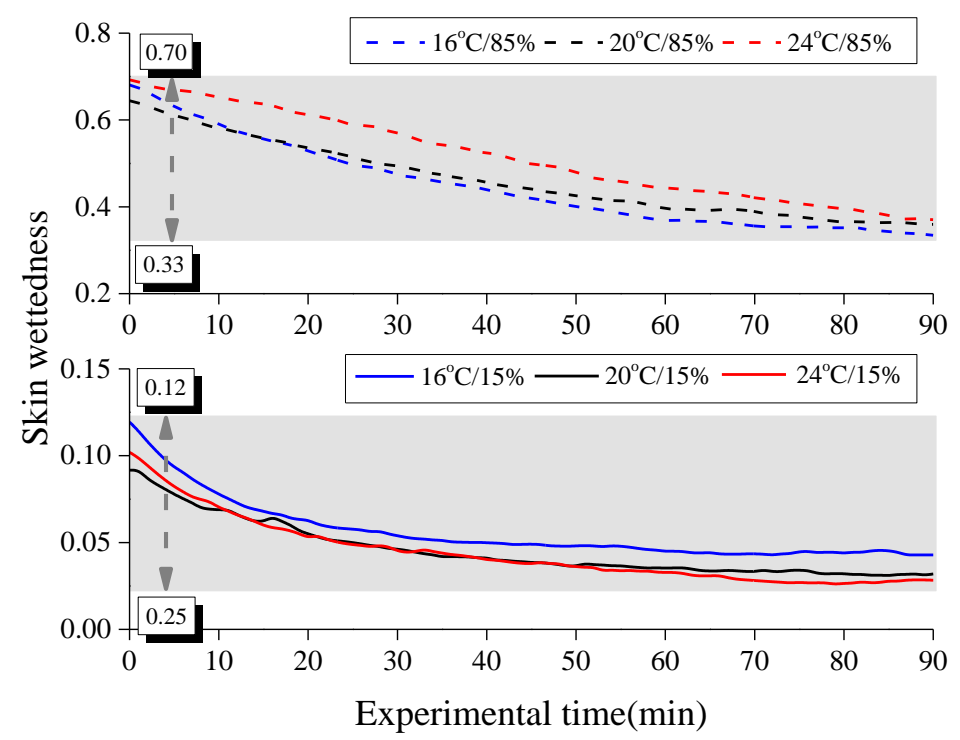

Figure 5 Changes in skin wettedness of subjects over time

\subsubsection{Blood flow at skin surface}

Body parts, mainly involving the extremities, such as the hands and feet, occupy a significant proportion in response to ambient temperatures in cold environments and thereby affect human thermal comfort [53]. In this study, the real time measurement of local skin blood flow at the back of the subjects' hands was conducted. The blood flow (unit: blood perfusion unit, BPU) per minute were averaged for 20 subjects during 90 min exposures. Figure 6 shows the changes in the subjects' blood flow in minutes under six conditions, where the blood flow fluctuated slightly over time, apart from the slight downward trend at $24{ }^{\circ} \mathrm{C} / 85 \% \mathrm{RH}$. In detail, under $15 \% \mathrm{RH}$, the mean blood flow of the subjects increased approximately from $400 \mathrm{BPU}$ at $16^{\circ} \mathrm{C}$, to $600 \mathrm{BPU}$ at $20^{\circ} \mathrm{C}$, to $800 \mathrm{BPU}$ at $24{ }^{\circ} \mathrm{C}$. This was owing to the body vasoconstriction to reduce heat loss from the extremities in cold conditions, thus leading to lower blood flow at lower temperatures [54]. Conversely, under $85 \% \mathrm{RH}$, the blood flow was higher at $16{ }^{\circ} \mathrm{C}$ and decreased with an increase of temperature. Compared to the physiological responses of 
the MST in Figure 4, it was inferred that cold stress was more significant under high humidity conditions, due to the great evaporative heat loss. In such a case, to avoid cold-induced strain, the body increases blood flow from the heart and peripheral to the skin concomitantly[55], resulting in a higher blood flow in cold-humid conditions. However, as the temperature increased, the physiological strain caused by the cold stimuli was attenuated and the blood flow decreased, which was not contradictory to the changes under $15 \% \mathrm{RH}$.
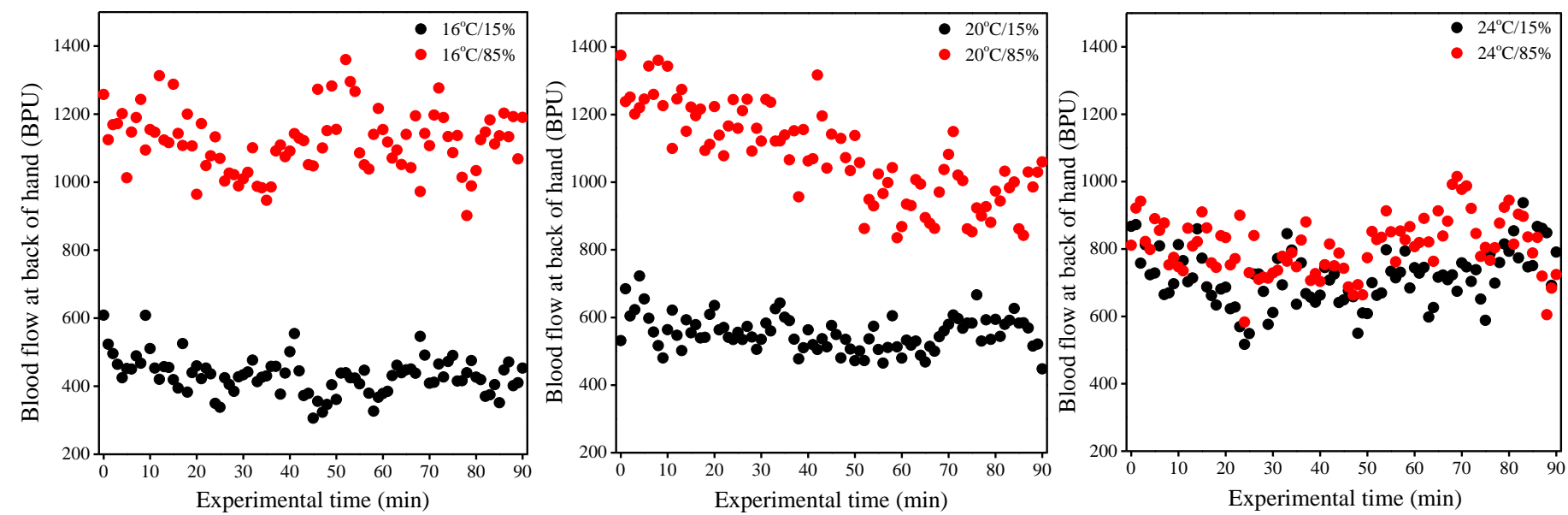

Figure 6 Changes in subjects' skin blood flow under different conditions

\subsubsection{Heat loss from skin surface}

According to Figures 4 and 6, the changes in skin temperature and blood flow were strongly related to the body heat loss of subjects at the skin surface. Therefore, the total

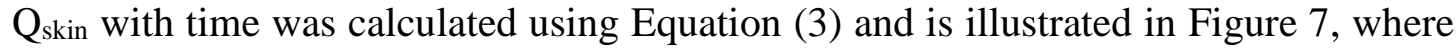
the $\mathrm{Q}_{\text {skin }}$ was observed being remarkably higher in cold-humid conditions than that in cold-dry conditions and decreasing slightly with time. For $15 \% \mathrm{RH}$, the maximum $\mathrm{Q}_{\text {skin }}$ value was observed at approximately $35 \mathrm{~W} / \mathrm{m}^{20} \mathrm{C}$ at $16^{\circ} \mathrm{C}$, which was higher than that at $24{ }^{\circ} \mathrm{C}$ (see solid lines in Figure 7). However, at $85 \% \mathrm{RH}$, Q skin was almost twice as high for the same temperature level, as indicated by the dotted lines in Figure 7; while the maximum $\mathrm{Q}_{\text {skin }}$ value was above $160 \mathrm{~W} / \mathrm{m}^{2 \circ} \mathrm{C}$ at $16{ }^{\circ} \mathrm{C} / 85 \% \mathrm{RH}$, comparing to approximately $90 \mathrm{~W} / \mathrm{m}^{20} \mathrm{C}$ at $16{ }^{\circ} \mathrm{C} / 15 \% \mathrm{RH}$. However, the $\mathrm{Q}_{\text {skin }}$ was reduced with increasing temperatures, and stabilised at $113.2 \mathrm{~W} / \mathrm{m}^{2 \circ} \mathrm{C}$ at $16{ }^{\circ} \mathrm{C} / 85 \% \mathrm{RH}$ and 73.5 $\mathrm{W} / \mathrm{m}^{2 \circ} \mathrm{C}$ at $16{ }^{\circ} \mathrm{C} / 15 \% \mathrm{RH}$, respectively at the end of experiments. Overall, the different changes in $\mathrm{Q}_{\text {skin }}$ under dry and humid conditions were closely in agreement with the changes in subjects' MST (Figure 4). 


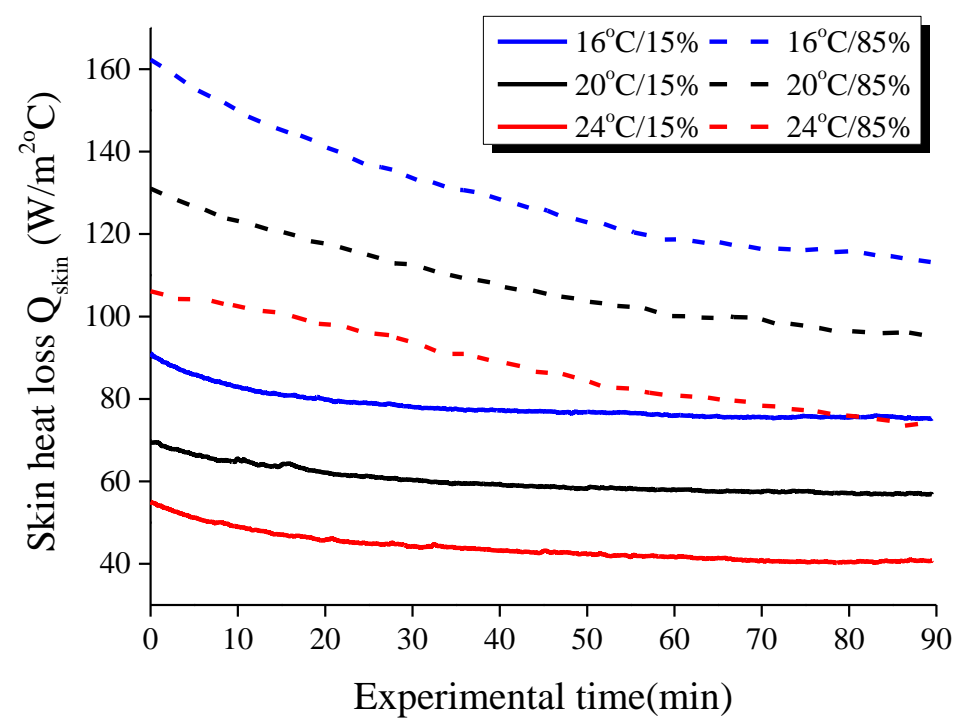

Figure 7 Changes in heat loss from subjects' skin surfaces under different conditions

We further calculated the total sensible and evaporative heat loss from the skin surface of subjects during 90 min using the experimental inputs; meanwhile the theoretical values based on the two-node model [47] were calculated. Figure 8 illustrates the total heat loss of subjects over the duration of the tests using the two methods, coupled with the sensible and evaporative heat loss. The corresponding values predicted by the model are demonstrated using the negative Y-axis in Figure 8. Significant differences were found between the experimental and predicted values with respect to the two humidity levels. At $15 \% \mathrm{RH}$, the sensible and evaporative heat losses in the experiments were slightly higher and close to the values predicted by the twonode model (blue and pink bars in Figure 8). The same was observed for the total heat loss from the skin surface, indicated by the brown bars in Figure 8. It was explained by the thermal and vapor resistances in clothing being close to the intrinsic values used in the two-node model. As a result, the model was applicable for predicting the heat transfer between the human body and environments without considering the effect of moisture in clothing. However, the prediction performance of the two-node model was challenged under $85 \%$ RH. As indicated by the grey box in Figure 8 , although the sensible heat losses were similar to the predicted values, the evaporative heat loss from the subjects' skin surface was overwhelmingly higher in the real experiments. For example, at $16^{\circ} \mathrm{C} / 85 \% \mathrm{RH}$, the predicted evaporative heat loss was only $45.88 \mathrm{~kJ}$, while the real value was approximately $568.46 \mathrm{~kJ}$, with the prerequisite of the same experimental parameters. As a result, the total heat loss was nearly $1161.75 \mathrm{~kJ}$ in the experiments, compared to that of $580.35 \mathrm{~kJ}$ in the model under $16^{\circ} \mathrm{C} / 85 \% \mathrm{RH}$. Although the deviations were narrowed when the temperature increased, they were still significant. According to Figure 8, such substantial differences were attributed to the variations in evaporative heat loss between the model and experiments. The model predicts the heat and mass transfer between the skin surface and environments through 
the clothing system under stable conditions; the moisture contents in clothing itself is not included. Therefore, the latent heat loss was simply based on the evaporation from the body skin surface, while the heat loss owing to vapor evaporation caused by the clothing was excluded in the calculation. The current study emphasized the transient process of moisture absorption and desorption in experimental clothes and considered the significant amount of heat loss caused by vaporisation in subjects' clothes during wearing. As a result, the obtained total heat loss from the subjects' skin surfaces were significantly higher than the predicted values in the model, indicating that the significant effect of heat and moisture loss in clothing should not be neglected in real situations in cold-humid environments.

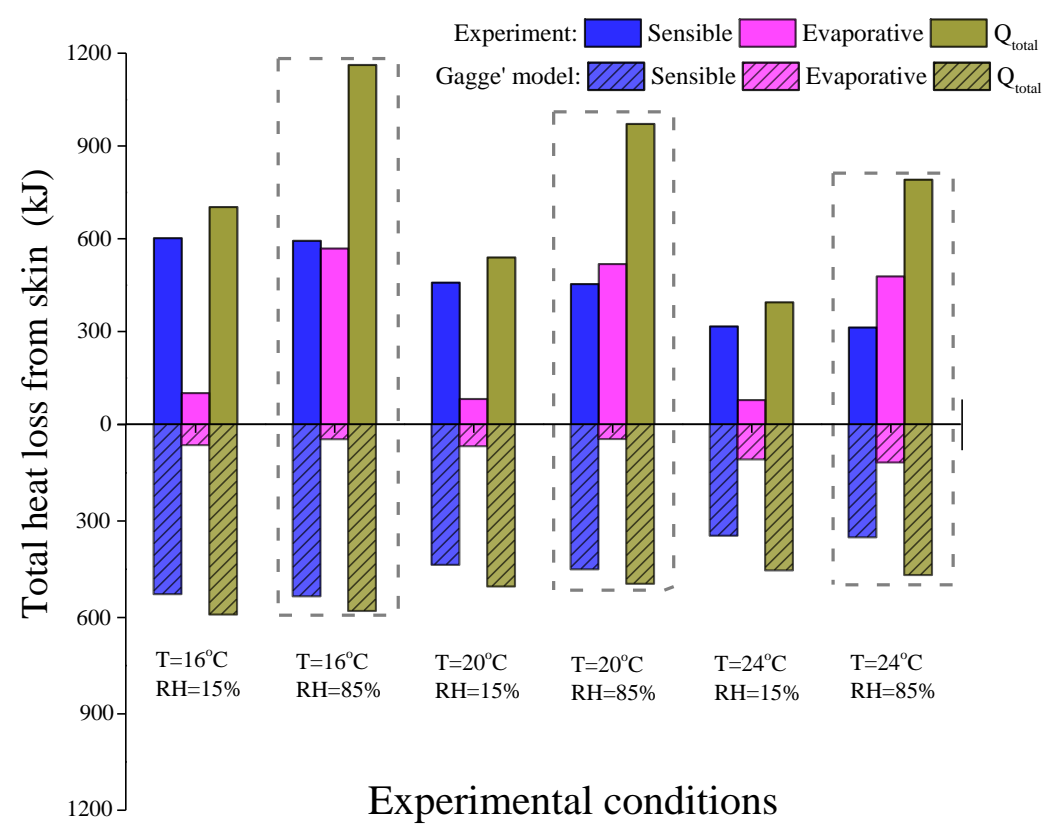

Figure 8 Comparison of total skin heat loss between experiments and predictions

\subsection{Thermal perceptions}

\subsubsection{TSV}

There are reasons to believe that the physiological responses of skin temperatures (Figure 4), local blood flow (Figure 6), and heat loss from the skin surface (Figures 7 and 8) remarkably affect subjects' thermal sensations. Therefore, Figure 9 illustrates the TSV responses of the subjects over time under six conditions. It is clearly observed that the TSV increased significantly when the temperature increased from $16{ }^{\circ} \mathrm{C}$ to 24 ${ }^{\circ} \mathrm{C}$. At each temperature level, the TSV were higher under $15 \% \mathrm{RH}$ than under $85 \% \mathrm{RH}$, which was in agreement with the MST in Figure 4 and the total heat loss in Figure 8. In particular, the biggest differences of TSV were found at the initial stage (marked in grey shading) and the deviation was up to 1 when comparing $16{ }^{\circ} \mathrm{C} / 15 \% \mathrm{RH}$ to 16 
${ }^{\circ} \mathrm{C} / 85 \%$ RH. This was because, owing to increased moisture absorbed in the experimental clothing ensembles at $85 \% \mathrm{RH}$, a significant amount of heat would be lost from the subjects and be used for vaporisation. As a result, subjects felt cooler under highly humid conditions and the TSV were significantly reduced.

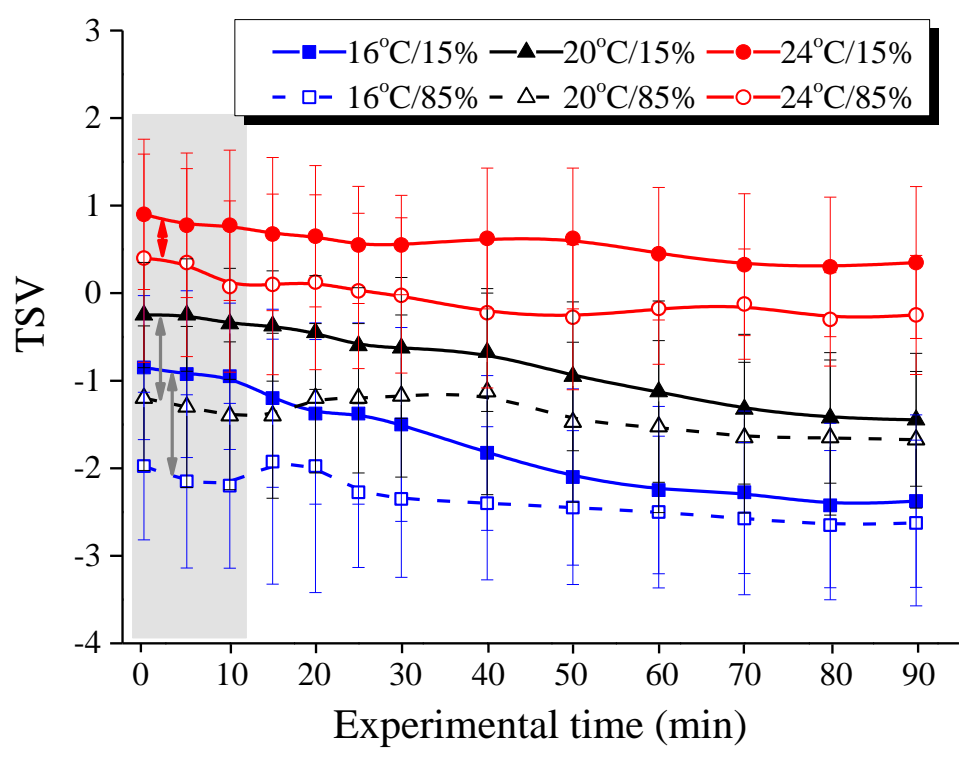

Figure 9 Subjects' thermal sensation changes with time during experiments

Given that the SET is a comprehensive index for reflecting the coupled effects of air temperature and humidity, the relation between the mean TSV of the subjects at a steady state and the SET was further examined, as shown in Figure 10. Meantime, the PMV, which reflects the changes of human thermal perceptions with the thermal environment based on the body heat balance, is also plotted in Figure 10. According to Figure 10, without considering the effect of moisture in clothing, the PMV increased linearly with increasing SET. In contrast, the linear relation was broken between the real TSV and SET. As indicated by the solid symbols in Figure 10, the mean TSV increased with temperature, but not with humidity. The TSV were lower under $85 \% \mathrm{RH}$ and a significant difference was found at $24^{\circ} \mathrm{C}$. At $16{ }^{\circ} \mathrm{C}$ and $20^{\circ} \mathrm{C}$, despite the statistical results being insignificant, the subject TSV were also comparably lower. The insignificant differences of TSV at lower temperatures may be attributed to the fact that the subjects' thermal sensations were close to thermal neutrality at $24{ }^{\circ} \mathrm{C}$; thus, the effects of the high and low humidity levels were significant. However, the temperatures of $16{ }^{\circ} \mathrm{C}$ and $20{ }^{\circ} \mathrm{C}$ were far beyond the comfort range, which would impose a very strong cold stimulus on all subjects [56]. In such cases, the temperature played a dominant role in all subjects feeling cold (TSV under -1) and the effect of air humidity was coverd to some degrees. 


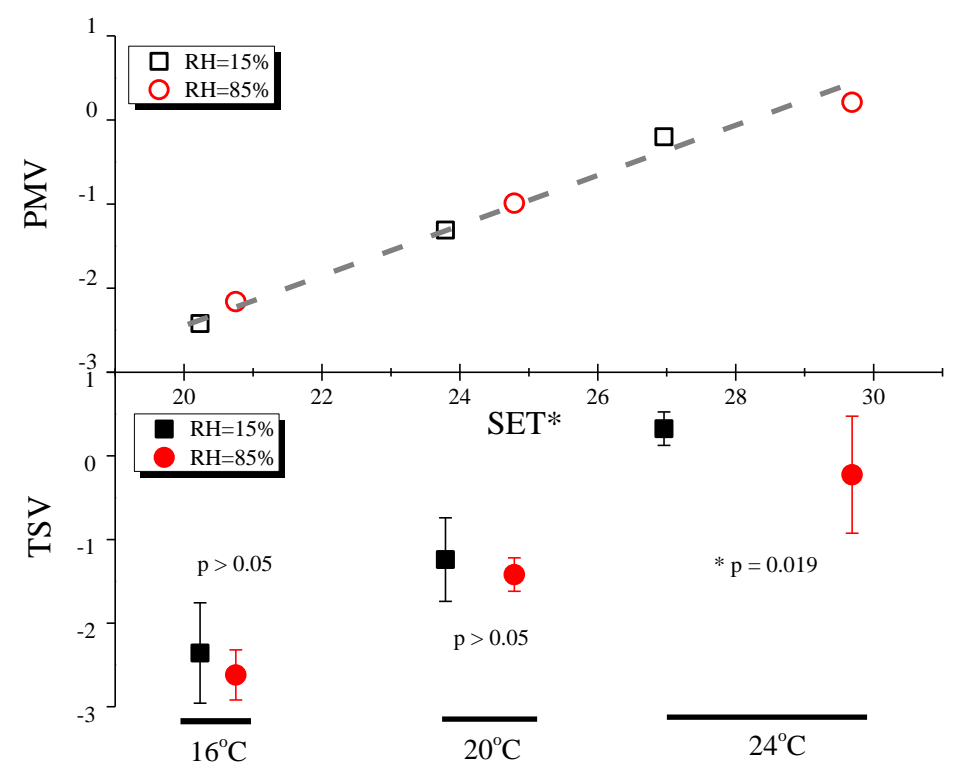

Figure 10 Comparisons between subject TSV and PMV

\subsubsection{Humidity sensation and acceptability}

The subjects' mean humidity sensation votes (HSV) and its relation to their humidity acceptability were evaluated, as illustrated in Figure 11. According to Figure 11, the air humidity had an observable influence on the subject HSV, which were all above 0 under $85 \%$ RH and below 0 under 15\% RH. With increasing/decreasing HSV, the acceptability to air humidity was reduced, exhibiting an inverted U-type with the HSV $\left(\mathrm{R}^{2}=0.64\right)$ in Figure 11 , which was similar to the relationship between thermal sensation and thermal comfort in previous studies $[57,58]$.

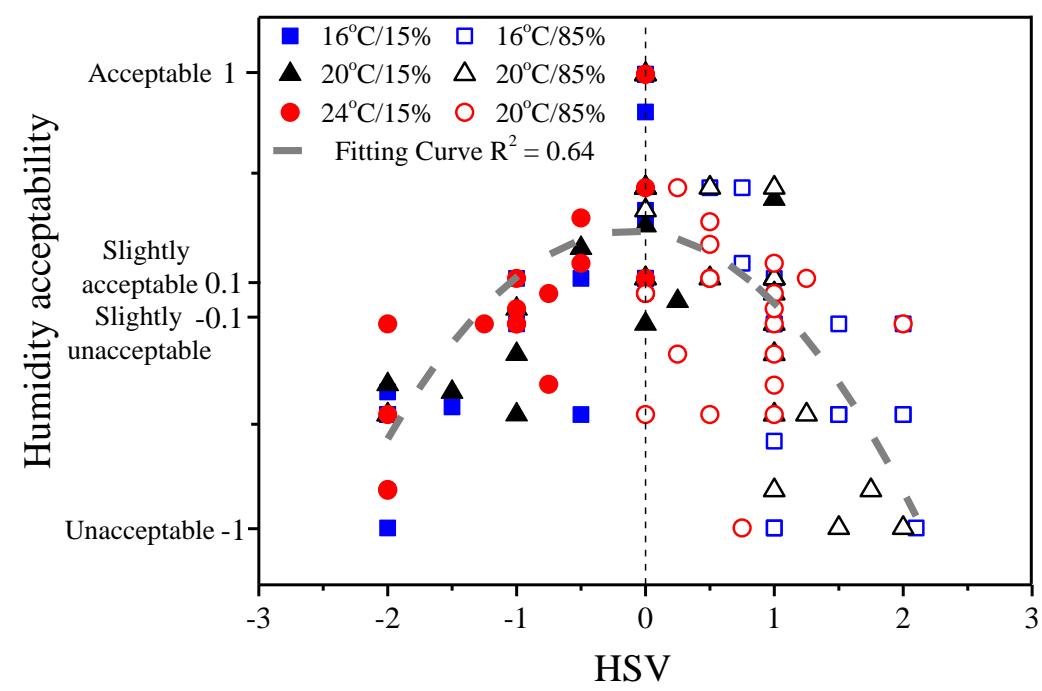

Figure 11 Relation between subjects' HSV and humidity acceptability 


\subsection{Evaluation of clothing microenvironments}

As analysed in Figures 4 to 11, the moisture in clothing has a significant effect on the subjects' physiological and psychological responses in cold environments; while it is commonly neglected in current thermal comfort evaluations. To quantify the coupling effect of the air temperature and humidity in clothing microenvironments, this study adopted the comprehensive index inner clothing effective temperature $\mathrm{T}_{\text {eff. }}$. According to Equations (4) and (5), the $T_{\text {eff }}$ values were calculated using experimental data of the microenvironment $\mathrm{T}_{\text {in }}$ and $\mathrm{RH}_{\mathrm{in}}$ and $\mathrm{P}_{\mathrm{sk}}$ at skin surface. The differences between the measured $\mathrm{T}_{\text {in }}$ and the calculated $\mathrm{T}_{\text {eff }}$ (i.e., the $\mathrm{T}_{\text {in }}$ minus the $\mathrm{T}_{\text {eff }}$ ) is first calculated and shown in Figure 12. It is clearly seen that the $\mathrm{T}_{\text {eff }}$ were both lower than the $\mathrm{T}_{\text {in }}$ for each condition that all the values were positive under six conditions. With the same $\mathrm{RH}$, the differences increased and were approximately $1.4{ }^{\circ} \mathrm{C}$ for $15 \% \mathrm{RH}$ and $1.8{ }^{\circ} \mathrm{C}$ for $85 \% \mathrm{RH}$ between $24{ }^{\circ} \mathrm{C}$ and $16{ }^{\circ} \mathrm{C}$. Interestingly, at each temperature level, the differences between $\mathrm{T}_{\text {in }}$ and $\mathrm{T}_{\text {eff }}$ were significantly higher at $15 \% \mathrm{RH}$ than at $85 \% \mathrm{RH}$. This suggested that the effects of microenvironment $\mathrm{RH}_{\text {in }}$ is non-ignorable. In this case, the $T_{\text {eff }}$ acts as a function of air temperature and humidity (Equation (3)) and can be better to reflect the coupled effects of clothing microenvironments.

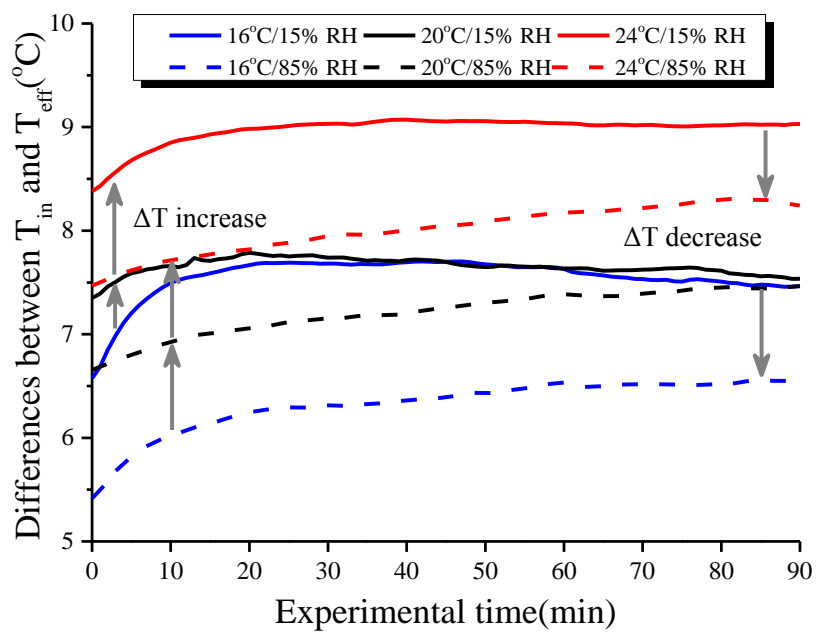

Figure 12 demonstrated the relation of $\mathrm{T}_{\text {in }}$ and $\mathrm{T}_{\text {eff }}$ that the $\mathrm{T}_{\text {eff }}$ took advantage of deploying the microenvironment air humidity in clothing. As a result, the $\mathrm{T}_{\text {eff }}$ was further examined to evaluate subject thermal sensation under moisture situations. Based on the data processing mentioned in section 2.6.3, the transient changes of $\mathrm{T}_{\text {eff }}$ and TSV during 90min and under six conditions are shown in Figure 13. From Figure 13, with the same $\mathrm{T}_{\text {eff, }}$, the thermal sensation was higher under $15 \% \mathrm{RH}$ (marked with solid symbols) than under $85 \% \mathrm{RH}$ (marked with hollow symbols), clearly revealing the 
negative moisture effects in clothing. With an increase in $\mathrm{T}_{\text {eff }}$, the TSV increased and the differences between $15 \% \mathrm{RH}$ and $85 \% \mathrm{RH}$ were narrowed. However, the TSV were still lower under $85 \% \mathrm{RH}$. Overall a significant linear relation $\left(\mathrm{R}^{2}=0.72\right)$ was observed

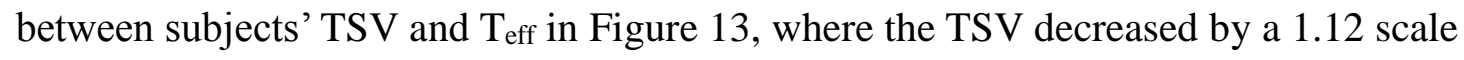
when decreasing the $\mathrm{T}_{\text {eff }}$ by $1{ }^{\circ} \mathrm{C}$. This indicates that subjects TSV are sensitive to air temperature and humidity between skin surface-clothing microenvironments and $\mathrm{T}_{\text {eff }}$ can be a good indicator to quantify the moisture effects in clothing on human thermal sensation.

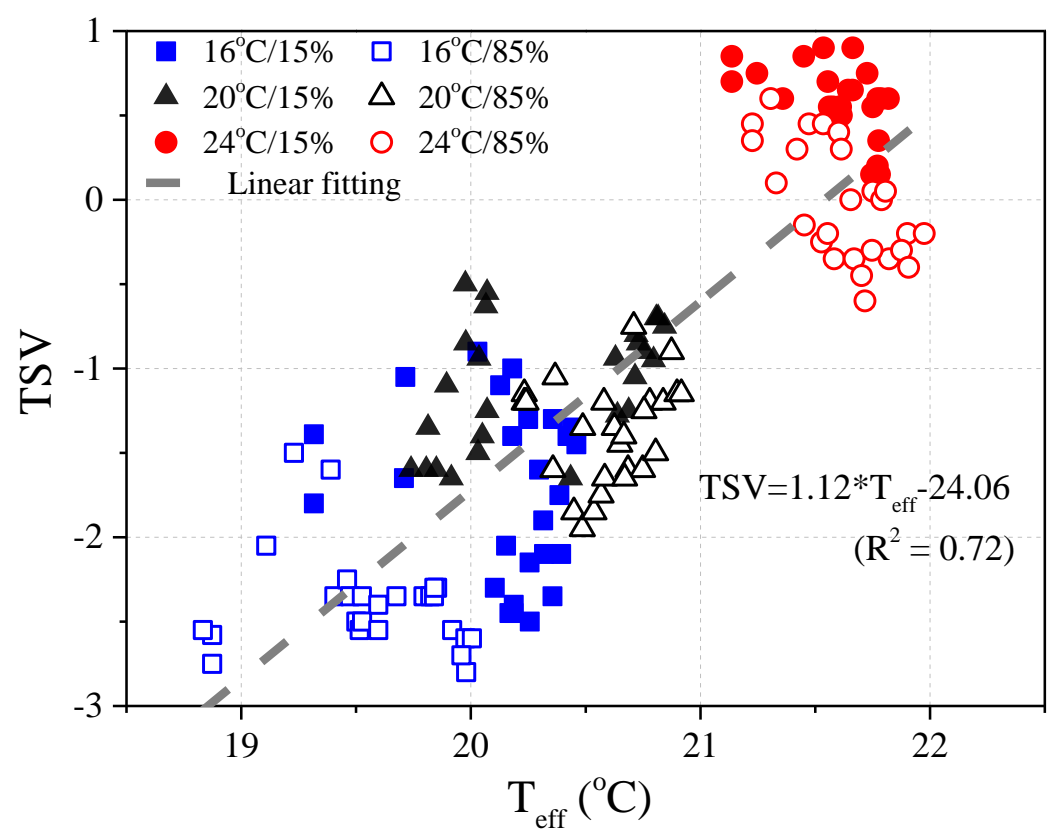

Figure 13 Relation between subjects' TSV and $\mathrm{T}_{\text {eff }}$ values during $90 \mathrm{~min}$

\section{Discussion}

\subsection{Negative role of clothing moisture in cold environments}

In theory, the thermal performance of clothing reduces the heat loss from the human body to the surroundings and in cold-dry environments, due to the low regain rates of clothing, the moisture transfer effect in clothing is negligible. In such cases, an increase in the air humidity decreases the temperature gradient between the skinclothing contact[59], restrains the evaporative heat loss from the human body and positively increases the thermal sensation[60]. Berglund [52] experimentally demonstrated that for a sedentary person, a $30 \%$ increase in relative humidity had the same effect on the thermal balance and thermal sensation as a $1{ }^{\circ} \mathrm{C}$ increase in temperature. This is in agreement with Li et al. [34], where the $\mathrm{RH}$ had a positive effect under cold temperatures. In his study, subjects who were on dried experimental clothes voted their thermal sensations from -2.2 to $-1.3(p<0.05)$ when the RH was increased 
from $15 \%$ to $85 \%$ at steady state at $16{ }^{\circ} \mathrm{C}$. Moreover, the subjects' TSV exhibited a strong linear relation with the SET.

However, those results are quite different from the current study, in which the effects of moisture sorption in clothing were considered. For example, based on the experimental data, subjects' initial TSV in Figure 9 were higher under 15\% RH than under $85 \% \mathrm{RH}$. Though the differences were reduced by the end, they were still higher under $15 \% \mathrm{RH}$. This responded to subjects' physiological regulations. In Figure 4, the MST at $16{ }^{\circ} \mathrm{C} / 85 \% \mathrm{RH}$ was $0.2{ }^{\circ} \mathrm{C}$ lower at steady state, compared to the predicted MST by the two-node model [47], which was $0.31{ }^{\circ} \mathrm{C}$ higher under $16{ }^{\circ} \mathrm{C} / 85 \% \mathrm{RH}$ than that under $16{ }^{\circ} \mathrm{C} / 15 \%$ RH. Furthermore, Figure 13 clearly indicates that regardless of the same $\mathrm{T}_{\text {eff, }}$ subjects expressed lower thermal sensations under $85 \% \mathrm{RH}$. Filingeri et al. [45] demonstrated that the skin cooling rate threshold for people's perception in sensing cold-dryness and cold-wetness was indeed between 0.07 and $0.14{ }^{\circ} \mathrm{C} / \mathrm{s}$. In fact, the wettedness sensation is a result of the integration of the somatosensory sub-modalities of touch and temperature [61,62]. That is, the wettedness sensation due to air humidity is partly dependent on temperature but in turn affects people's thermal sensations in cold environments. In this study, because the changes in $\mathrm{T}_{\text {in }}$ and $\mathrm{RH}_{\mathrm{in}}$ at $85 \% \mathrm{RH}$ conditions were transient processes during 90 min exposure (Figure 3), such dynamic changes sensed by skin receptors, coupled with the humidity sensation perceived by subjects, aggravated the cooling sensation of subjects under cold-humid environments. Several previous researches $[3,26]$ had addressed the "after chill" effect caused by moisture evaporation in clothing and its positive role on body heat loss for fire-fighters, where sweating occurs in hot environments. However, in cold environments, such an effect is negative and the moisture desorption and evaporation within clothes may conversely reduce the clothing thermal insulation[26] and promote heat loss from the human body, leading to a substantially cooler feeling for people in cold environments.

\subsection{Evaluation of clothing moisture effects on human thermal comfort}

The clothing thermal insulation measured under dry conditions is frequently used to calculate the dry heat loss. However, the effects of moisture on clothing thermal resistance and heat transfer have been neglected in most cases [26]. Wang [35] measured the influence of clothing material on "wet" conductive thermal resistance and found that due to the higher amount of moisture contained, cotton fabric tended to exhibit a low thermal resistance. In this study, significant regain rates of approximately $10 \%$ were observed in cotton clothes at $85 \% \mathrm{RH}$ (Table 2), meaning that increased moisture contents were absorbed in the clothes prior to dressing. Since the thermal conductivity of water is much greater than that of air, the effective thermal resistance of the wetted clothes would decrease [63] with an increase in moisture regain. As a result, additional sensible heat loss caused by clothes is predictable during the 
experiments, which results in lower MST (Figure 4) and TSV (Figure 10) of subjects at $85 \% \mathrm{RH}$, in contrast to that under dried clothing conditions [34].

Furthermore, the clothing system not only transmits a significant amount of heat through itself, but stores a certain amount of heat for warming the clothes and moisture evaporation. During experiments, when subjects wore the clothes, their skin temperatures were higher than the temperatures of clothing. Thus, the moisture equilibrium between the clothes and ambient environments was broken and the moisture present in the clothing underwent the phase changes from liquid to vapour, which can be reflected by the significant mass loss of clothes (Figure 2), further promoting deceases in the MST and TSV.

The remarkable "after chill" effect was verified by the calculated evaporative heat loss and total $\mathrm{Q}_{\text {skin }}$ in Figures 7 and 8. The heat losses from skin surface at 85\% RH were significantly higher than $15 \%$ RH (Figure 7), so were the accumulated evaporative heat loss and total heat loss during the 90min period (Figure 8). In such a case, if a constant metabolic heat generation is assumed, subjects may have negative heat storage under the testing scenarios and suffer from cold strain to a certain degree. However, in fact, in cold conditions the body metabolic rates would be enhanced to maintain the balance between the heat generation and heat loss [64]. These changes in metabolic rates are speculated to offset the physiological and psychological responses of subjects during experiments, but this phenomenon requires further investigation.

\subsection{Limitations and further work}

Several limitations are stated here in order to provide an improved interpretation of the results in the current study. An accurate determination of the thermal resistance and moisture vapour resistance of clothing is crucial to predict human physiological responses and evaluate thermal comfort. However, the thermal behaviours of clothing in an active person are complex and difficult to quantify. As the moisture absorption and desorption in clothing changes dynamically in high humidity conditions, the clothing thermal resistance and vapor resistance may change gradually with time. This study focuses more on the relative changes between different conditions and the estimations of the heat loss using constant values in section 3.2.4 may have some deviations from real situations. Various existing models that predict the heat and mass transfer of clothing are usually combined with human physiological models, while clothing thermal and vapor resistances are still adopted as constants[65, 66]. Several other studies focusing on clothing performance improvement have been based on the theoretical analyses and experimental measurements of fabric materials [67-69], rather than of whole clothing under actual wearing conditions. This study makes the premised assumption of using the intrinsic thermal and vapour resistance of clothing when calculating the sensible and evaporative heat loss from the skin surface. However, 
further studies are necessary to explore the dynamic moisture absorption and desorption in clothing assembly to determine the dynamic characteristics of the thermal and vapour resistances of clothing under wearing conditions, thereby evaluating human thermal comfort more accurately.

This study bases on the research question of occupant cold and humid feelings in winter in HSCW zone and takes the moisture effects in clothing as a breakthrough point. However, due to the limited exposure time of $90 \mathrm{~min}$ in experiments, there were some situations where the metrics did not reach steady state, for example, in Figures 3 and 5. The transient effects of moisture in clothing on subject thermal sensation may not be able to answer whether subjects would feel as warmer as theoretical predictions under $85 \% \mathrm{RH}$ after a long term exposure, where the moisture effects in clothing were weakened. One question should be noted that subjects in experiments wore thin clothes without overcoat. This led to a fact that the body skin temperatures were much higher than the temperatures of clothes so that moisture in clothing evaporated quickly. In reality, people would wear thick overcoat in winter and the transient moisture absorption and desorption may exist consistently in human body-clothing systemsambient environments in high humid climates, maintaining a dynamic thermal balance. Therefore, in a long run, whether such moisture effects on wears' comfort would disappear or last should be examined based on further experiments and field investigations. Moreover, as the "part space-part time" intermittent heating mode is highly recommended in HSCW zone for winter heating [70], coupled with higher air humidity outdoors and the preferred window opening habits of occupants [9], the indoor high air humidity and moisture may not be alleviated significantly during heating situations, especially for residential buildings. In that case, this study revealed the negative effect of moisture evaporation in clothing enhancing body heat loss, which should not be neglected. However, how to offset the moisture effects, how to design the heating temperature setting points, and whether there would be different for residential buildings and for office buildings are under explored in future research.

\section{Conclusions}

Based on a series of wearing experiments in a climate chamber, this study has explored the effects of moisture in clothing on human thermal responses, and revealed the negative moisture absorption and desorption in clothing microenvironments in cold climates. Some conclusions can be drawn as follows.

1) The subjects' mean skin temperatures increased with temperatures but conversely decreased when comparing $85 \% \mathrm{RH}$ to $15 \% \mathrm{RH}$, due to the moisture-induced heat loss in the clothing. The initial skin wettedness was approximately 0.7 at $85 \% \mathrm{RH}$, due to the higher clothing regain rates, and gradually stabilised at 0.33 . 
2) The total heat loss from skin at $85 \% \mathrm{RH}$ was almost twice as high as that at $15 \%$ $\mathrm{RH}$ for the same temperature level. The experimentally accumulated evaporative and total heat losses at the skin surface were higher compared to those of the twonode model, which was attributed to the additional heat and mass losses caused by the moisture vapour evaporation in the clothing.

3) Moisture evaporation in experimental clothes aggravated subjects' sensations of cold under $85 \% \mathrm{RH}$ and the changes of TSV were consistent with the mean skin temperature, thereby explaining the mechanism underlying people significant colder feelings in cold-humid conditions.

4) The inner clothing effective temperature $T_{\text {eff }}$ was proposed to evaluate the coupled effects of air temperature and humidity in the clothing microenvironments. The

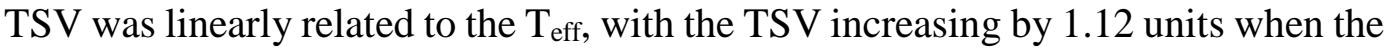
$\mathrm{T}_{\text {eff }}$ increased by $1{ }^{\circ} \mathrm{C}$. The findings are beneficial for quantifying the moisture effects in clothing on human thermal comfort and guiding indoor thermal environment designs for heating in cold-humid climates.

\section{Acknowledgements}

This work was supported by the Ministry of Science and Technology of the People's Republic of China (Grant No: 2016YFC0700301 and 2017YFC0702704), associated with the UK-China collaborative project funded by the National Natural Science Foundation of China and UK Engineering and Physical Sciences Research Council (NSFC 51561135002/ EPSRC EP/N009797/1). The authors would also thank for the subjects for their participation.

\section{References:}

[1] P.O. Fanger, Thermal comfort. Danish Technical Press, Copenhagen, 1970.

[2] Z. Wang, L. Zhang, J. Zhao, Y. He, Thermal comfort for naturally ventilated residential buildings in Harbin, Energ Build. 42(12)(2010)2406-2415.

[3] M.V. Vivekanandan, S. Sreenivasan, Dynamic transportation of water vapor through cotton and polyester-cotton blended fabrics: Part I: Indices characterizing moisture buffering and their interrelationships, J Eng Fiber Fabr. 7(4)(2012)70-80.

[4] G.S. Brager, R.J.D. Dear, Thermal adaptation in the built environment: a literature review, Energ Build. 27(1)(1998)83-96.

[5] H Liu, W.Q. Zheng, B.Z Li, M.L. Tan, Y.F. Gao, Z.X. Jin, Behavioural adaptation of indoor thermal environment in hot-summer and cold-winter zone, J Cent South Univ. 42(6)(2011)1805-1812.

[6] I. Nam, J. Yang, D. Lee, E. Park, J.R. Sohn, A study on the thermal comfort and clothing insulation characteristics of preschool children in Korea, Build Environ. 92(2015)724-733. 
[7] B. Cao, Y. Zhu, Q. Ouyang, X. Zhou, L. Huang, Field study of human thermal comfort and thermal adaptability during the summer and winter in Beijing, Energ Build. 43(5)(2011)1051-1056.

[8] G. Havenith, Metabolic rate and clothing insulation data of children and adolescents during various school activities, Ergonomics. 50(10)(2007)1689-1701.

[9] H. Liu, Y. Wu, B. Li, Y. Cheng, R. Yao, Seasonal variation of thermal sensations in residential buildings in the Hot Summer and Cold Winter zone of China, Energ Build. 140(2017)9-18.

[10] C. Morgan, R. De Dear, Weather, clothing and thermal adaptation to indoor climate, Clim Res. 24(3)(2003)267-284.

[11] M.D. Carli, B.W. Olesen, A. Zarrella, R. Zecchin, People's clothing behaviour according to external weather and indoor environment, Build Environ. 42(12)(2007)3965-3973.

[12] J.F. Nicol, I.A. Raja, A. Allaudin, G.N. Jamy, Climatic variations in comfortable temperatures: the Pakistan projects, Energ Build. 30(3)(1999)261-279.

[13] F. Haldi, D. Robinson, Modelling occupants' personal characteristics for thermal comfort prediction, Int J Biometeorol. 55(5)(2011)681-694.

[14] R. De Dear, Developing an adaptive model of thermal comfort and preference, ASHRAE Trans. 104(1)(1998)73-81.

[15] W. Liu, D. Yang, X. Shen, P. Yang, Indoor clothing insulation and thermal history: A clothing model based on logistic function and running mean outdoor temperature, Build Environ. 135(1)(2018)142-152.

[16] A.M. Schneider, B.V. Holcombe, Coolness of 'cool wool' fabrics. In: The 8th International Wool Textile Research Conference, Christchurch, New Zealand, 5(1990)215-224.

[17] A.M. Schneider, B.V. Holcombe, L.G. Stephens, Enhancement of coolness to the touch by hygroscopic fibers. I. Subjective trials, Textile Res J. 66(8)(1996)515-520.

[18] G. Havenith, I. Holmér, K. Parsons, Personal factors in thermal comfort assessment: clothing properties and metabolic heat production, Energ Build. 34(6)(2002)581-591.

[19] R. Nielsen, T.L. Endrusick, Sensations of temperature and humidity during alternative work/rest and the influence of underwear knit structure, Ergonomics. 33(2)(1990)221.

[20] M Takanokura, Effect of change in wettedness on wear comfort during exercise with sweating, Bull Showagakuin Jr Coll. 33(1997)63-72.

[21] N.R.S. Hollies, A.G. Custer, C.J. Morin, M.E. Howard, A Human Perception Analysis Approach to Clothing Comfort, Text Res J. 49(10)(1979)557-564.

[22] K. Hong, H. Nrs, S.M. Spivak, Dynamic moisture vapor transfer through textiles-Part I: Clothing hygrometry and the influence of fiber type, Text Res J. 58(12)(1988)697-706.

[23] D.M. Scheurell, S.M. Spivak, H. Nrs, Dynamic surface wetness of fabrics in relation to clothing comfort, Textile Res J. 55(7)(1985)394-399.

[24] H. Yan, Y. Mao, L. Yang, Thermal adaptive models in the residential buildings in different climate zones of Eastern China, Energ Build. 141(2017)28-38.

[25] J. Fan, X.Y. Cheng, Heat and Moisture Transfer with Sorption and Phase Change Through Clothing Assemblies Part I: Experimental Investigation, Text Res J. 75(2)(2005)99-105.

[26] J. Fan, Y.S. Chen, W. Zhang, Clothing thermal insulation when sweating and when non-sweating , Elsevier Ergonomics Book. 3(05)(2005)437-443. 
[27] CCG. Schacher, Evaluating the Effects of Moisture on the Thermal Protective Performance of Firefighter Protective Clothing in Low Level Heat Exposures. Raleigh, North Carolina: North Carolina State University, 2007.

[28] M. Fu, M.Q. Yuan, W.G. Weng, Modeling of heat and moisture transfer within firefighter protective clothing with the moisture absorption of thermal radiation, Int J Therm Sci. 96(2015)201-210.

[29] G. Song, S. Paskaluk, R. Sati, E.M. Crown, J.D. Dale, M. Ackerman, Thermal protective performance of protective clothing used for low radiant heat protection, Text Res J. 81(3)(2010)311-323. [30] R.L. Barker, C. Guerth-Schacher, R.V. Grimes, H. Hamouda, Effects of Moisture on the Thermal Protective Performance of Firefighter Protective Clothing in Low-level Radiant Heat Exposures, Text Res J. 76(1)(2006)27-31.

[31] D. Ding, T. Tang, G. Song, A. Mcdonald, Characterizing the performance of a single-layer fabric system through a heat and mass transfer model-Part I: Heat and mass transfer model, Text Res J. 81(9)(2011)398-411.

[32] F. Zhu, K. Li, Numerical Modeling of Heat and Moisture Through Wet Cotton Fabric Using the Method of Chemical Thermodynamic Law Under Simulated Fire, Fire Technol. 47(3)(2011)801-819.

[33] B. Cao, M. Luo, M. Li, Y. Zhu, Too cold or too warm? A winter thermal comfort study in different climate zones in China, Energ Build. 133(2016)469-477.

[34] C. Li, H. Liu, B. Li, A. Sheng, Seasonal effect of humidity on human comfort in a hot summer/cold winter zone in China, Indoor Built Environ. Available online, 10 Jan, 2018.

[35] F. Wang, D. Lai, W. Shi, M. Fu, Effects of fabric thickness and material on apparent 'wet' conductive thermal resistance of knitted fabric 'skin' on sweating manikins, J Therm Biol. 70(Part A)(2017)69-76.

[36] ASHRAE Handbook 2013, Foundamentals-Chapter 9 Thermal Comfort, in: ASHRAE Technical Committees, 2013.

[37] W.E. Morton, J.W.S. Hearle, Physical properties of textile fibres (Fourth edition), Woodhead Publishing Series in Textiles. (2008) pp 625-642.

[38] F. Faul, E. Erdfelder, A.G. Lang, A. Buchner, G*Power 3: a flexible statistical power analysis program for the social, behavioral, and biomedical sciences, Behav Res Methods. 39(2)(2007)175-191. [39] L. Lan, Z. Lian, Application of statistical power analysis-How to determine the right sample size in human health, comfort and productivity research, Build Environ. 45(5)(2010)1202-1213.

[40] World Medical Association(WMA). WMA Declaration of Helsinki - Ethical Principles for Medical Research Involving Human Subjects, in 64th WMA General Assembly, Fortaleza, Brazil, October 2013. [41] A.P. Gagge, Heat exchange between human skin surface and thermal environment, Handbook of Physiology Reaction to Environment Agents. 9(1977)

[42] L.G. Berglund, D.J. Cunningham, Parameters of human discomfort in warm environments, ASHRAE Trans. 92(2B)(1986).

[43] ASHRAE 55: 2013, Thermal Environmental Conditions for Human Occupancy, in: American Society of Heating, Refrigerating and Air-Conditioning Engineers, Atlanta, GA, 2013.

[44] M. Raccuglia, B. Sales, C. Heyde, G, Havenith, S. Hodder, Clothing comfort during physical exercise-Determining the critical factors, Appl Ergon. 73(2018)33-41.

[45] Filingeri, Davide, Redortier, Bernard, Hodder, S. G, Havenith, George, The role of decreasing contact temperatures in the perception of wetness on the skin, In: Proceedings of the 15th International 
Conference on Environmental Ergonomics, Queenstown, New Zealand, 11-15 February 2013, p. 174.

[46] T. Yao, Physiology(8th) (In Chinese). Fudan University Press, Shanghai, 2005.

[47] A.P. Gagge, An Effective Temperature Scale Based on a Simple Model of Human Physiological Regulatory Response, ASHRAE Trans. 77(1)(1971)21-36.

[48] H. Kubota, N. Kamata, Prediction of mean skin temperature as an index of human response to the thermal environment. J Architect Plan 65(532)(2000)79-85.

[49] J.H. Choi, V. Loftness, Investigation of human body skin temperatures as a bio-signal to indicate overall thermal sensations, Build Environ. 58(15)(2012)258-269.

[50] Y. Zhan, Study Heat and Moisture Transmission Characteristics and Measuring and Evaluating Method of Human-Clothiing-Environment System. Beijing: Academy of Military Sciences PLA China, 2006. (In Chinese)

[51] N. Kakitsuba, Physiological responses to changes in relative humidity under thermally neutral, warm and hot conditions, J Therm Biol. 59(2016)86-91.

[52] L.G. Berglund, Comfort and humidity, ASHRAE Trans. (1998)35-41.

[53] H. Zhang, E. Arens, C. Huizengga, T. Han, Thermal sensation and comfort models for non-uniform and transient environments: Part I: Local sensation of individual body parts, Build Environ. 45(2)(2010)380-388.

[54] J. Yu, G. Cao, W. Cui, Q. Ouyang, Y. Zhu, People who live in a cold climate: thermal adaptation differences based on availability of heating, Indoor Air. 23(4)(2013)303-310.

[55] H.A.M. Daanen, Finger cold-induced vasodilation: a review, Eur J Appl Physiol. 89(5)(2003)411426.

[56] M. Luo, B. Cao, Q. Ouyang, Y. Zhu, Indoor human thermal adaptation: dynamic processes and weighting factors, Indoor Air. 27(2)(2016)273-281.

[57] M. Luo, B. Cao, X. Zhou, M. Li, J. Zhang, Q. Ouyang, Y. Zhu, Can personal control influence human thermal comfort? A field study in residential buildings in China in winter, Energ Build. 72(2)(2014)411-418.

[58] M. Luo, B. Cao, J. Damiens, B. Lin, Y. Zhu, Evaluating thermal comfort in mixed-mode buildings: A field study in a subtropical climate, Build Environ. 88(2014)46-54.

[59] Y.I. Li, A.S.W. Wong, Clothing Biosensory Engineering, Woodhead Publishing Series in Textiles, 8(3)(2006)93-115.

[60] H. Tsutsumi, S.I. Tanabe, J. Harigaya, Y. Iguchi, G. Nakamura, Effect of humidity on human comfort and productivity after step changes from warm and humid environment, Build Environ. 42(12)(2007)4034-4042.

[61] R. Ackerley, H. Olausson, J. Wessberg, F. Mcglone, Wetness perception across body sites, Neurosci Lett. 522(1)(2012)73-77.

[62] Wouter M.Bergmann Tiest, N. Dolfine Kosters, Astrid M.L.Kappers, Hein A.M. Daanen, Haptic perception of wetness, Acta Psychologica. 141(2)(2012)159-163.

[63] A.M. Schneider, B.N. Hoschke, H.J. Goldsmid, Heat transfer through moist fabrics, Text Res J. 62(2)(2015)61-66.

[64] M. Luo, X. Zhou, Y. Zhu, J. Sundell, Revisiting an overlooked parameter in thermal comfort studies, the metabolic rate, Energ Build. 118(2016)152-159. 
[65] K. Katić, R. Li, W. Zeiler, Thermophysiological models and their applications: A review, Build Environ. 106(2016)286-300.

[66] C. Voelker, S. Hoffmann, O. Kornadt, E. Arens, H. Zhang, Heat and moisture transfer through clothing, In: IBPSA Building Simulation 2009, University of Strathclyde, Glasgow, Scotland, 27-30, July, 2009.

[67] J. Fan, X. Cheng, X. Wen, W. Sun, An improved model of heat and moisture transfer with phase change and mobile condensates in fibrous insulation and comparison with experimental results, Int $\mathbf{J}$ Heat Mass Tran. 47(10)(2014)2343-2352.

[68] J. Fan, Y.S. Chen, Measurement of clothing thermal insulation and moisturevapour resistance using a novel perspiring fabric thermalmanikin, Meas Sci Technol. 13(13)(2002)1115.

[69] Z. Wang, Y. Li, Y.L. Kowk, C.Y. Yeung, Mathematical Simulation of the Perception of Fabric Thermal and Moisture Sensations, Text Res J. 72(4)(2002)327-334.

[70] Z. Wang, R.D. Dear, B. Lin, Y. Zhu, Q. Ouyang, Rational selection of heating temperature set points for China's hot summer-cold winter climatic region, Build Environ. 93(2015)63-70. 